\begin{tabular}{|c|c|c|c|c|c|}
\hline \multicolumn{6}{|c|}{ DISTRIBUTION SHEET } \\
\hline To & \multirow{2}{*}{\multicolumn{3}{|c|}{$\begin{array}{l}\text { From } \\
\text { Process Laboratories \& } \\
\text { Technology }\end{array}$}} & \multicolumn{2}{|l|}{ Page 1 of 1} \\
\hline Distribution & & & & \multicolumn{2}{|c|}{ Date January 23, 1995} \\
\hline \multicolumn{4}{|c|}{ Project Title $/$ Work Order } & \multicolumn{2}{|c|}{ EDT No. 600500} \\
\hline \multicolumn{4}{|c|}{$\begin{array}{l}\text { Number of Core Samples: Mean Concentrations and Confidence } \\
\text { Intervals }\end{array}$} & \multicolumn{2}{|c|}{ ECN No. NA } \\
\hline Name & MSIN & $\begin{array}{l}\text { Text } \\
\text { With All } \\
\text { Attach. }\end{array}$ & Text Only & $\begin{array}{l}\text { Attach./ } \\
\text { Appendix } \\
\text { Only }\end{array}$ & $\begin{array}{l}\text { EDT/ECN } \\
\text { Only }\end{array}$ \\
\hline
\end{tabular}

OFFSITE

U.S. Department of EnergyHeadquarters

12800 Middlebrook Road

Trevion II, EM-36

Germantown, MD 20874

K. T. Lang .

J. Poppiti

ONSITE

U.S. Department of Energy-

Richland Operations office

R. E. Gerton

J. H. Clark

57-54

S7-54

$\mathrm{K} 5-12$

K7-97

$\mathrm{K} 9-81$

$\mathrm{K} 5-12$

$\mathrm{K} 5-12$

P7-35

K9-78

P7-25

D. H. Stracha

J. L. Swanson

Westinghouse Hanford Company

W. T. Alumkal

H. Babad

M. L. Bell

D. R. Bratzel

D. J. Braun

T. M. Brown

R. D. Cromar

S. J. Eberlein

G. D. Forehand

C. S. Haller

L. Jensen (20)

J. R. Jewett

T. J. Kelley

M. J. Kupfer

S. L. Lambert

H. A. Payne

R. S. Popielarczyk

G. F. Raphael

D. A. Reynolds

L. H. Sasaki

B. C. Simpson

J. P. Sloughter

D. J. Hashenfelder

T. L. Welsh

S. R. Wi Imarth

H. I. Hinters

Central Files
O.S.T.I. (2)
57-85

$57-30$

T6-03

s7-31

H4-66

R2- 12

T6-07

R2- 12

S7-31

$R 2-12$

T6-07

T6-09

s7-30

H5- 49

H5-27

s7-14

R1-30

R2- 12

R2-11

R2- 12

R2- 12

H5- 27

H5-27

T6-07

T6-07

T6-50

L8-04

L8-07 


\section{EDT 600500}

2. To: (Receiving Organization)

Distribution
5. Proj./Prog./Dept./Div.: WM

8. Originator Remarks:

Release of document "Number of Core Samples: Mean

3. From: (Originating Organization)
Process Laboratories and
Technology
6. Cog. Engr.:
L. Jensen

3. From: (Originating Organization)

6. Cog. Engr.:

L. Jensen

\section{Concentrations and Confidence Intervals"}

Process Laboratories and

11. Receiver Remarks:

4. Related EDT No.:

$N / A$

7. Purchase Order No.:

N/A

9. Equip./Component Mo.: $N / A$

10. System/Bldg./Facility: $N / A$

12. Hajor Assm. Dwg. No.: $N / A$

13. Permit/Permit Application No.: $N / A$

14. Required Response Date: 1-16-95

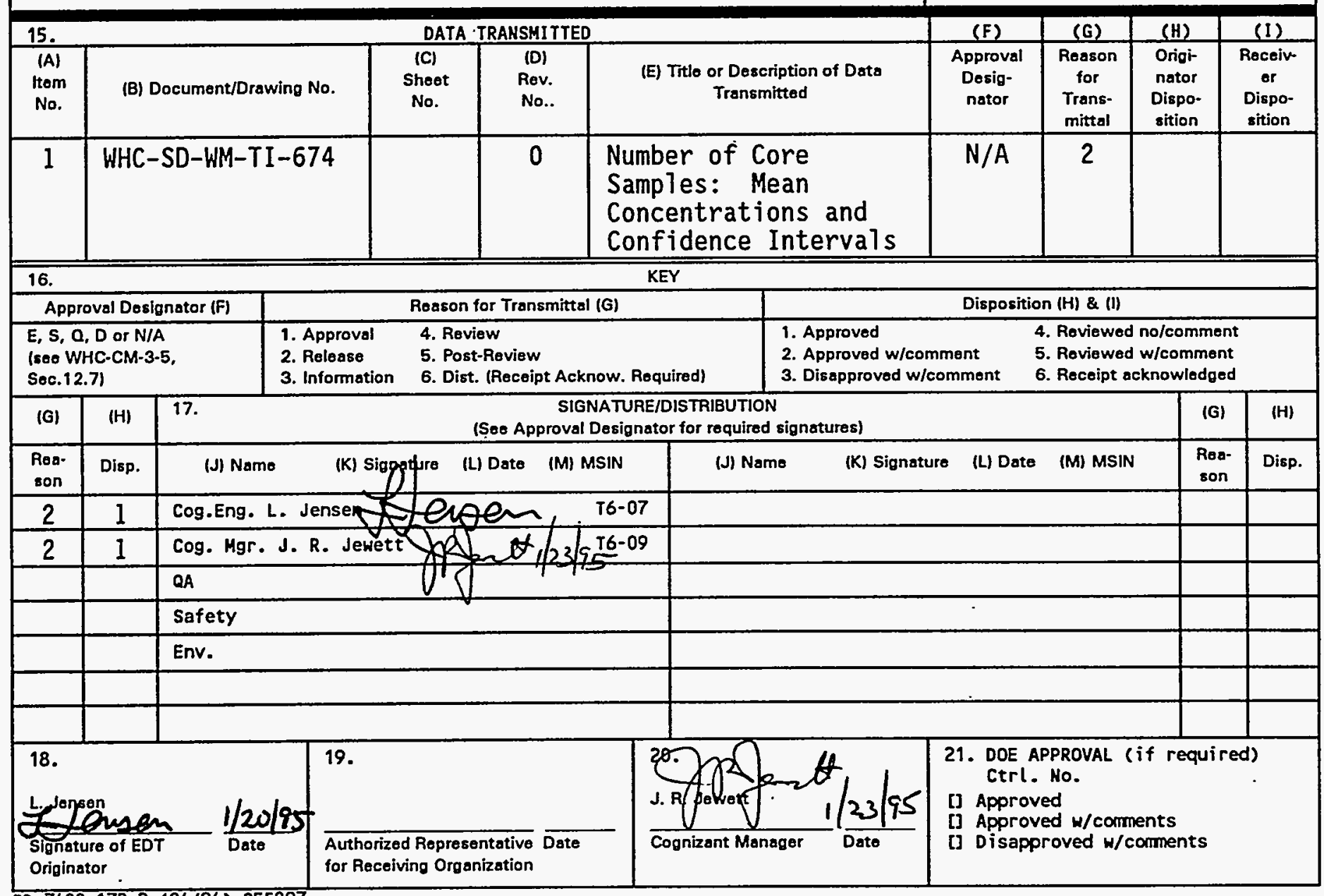




\section{DISCLAIMER}

Portions of this document may be illegible in electronic image products. Images are produced from the best available original document. 


\section{RELEASE AUTHORIZATION}

Document Number: WHC-SD-WM-TI-674, REV 0

Document Title: NUMBER OF CORE SAMPLES: MEAN CONCENTRATIONS AND CONFIDENCE INTERVALS

Release Date: $\quad 1 / 24 / 95$

\section{This document was reviewed following the procedures described in WHC-CM-3-4 and is:}

\section{APPROVED FOR PUBLIC RELEASE}

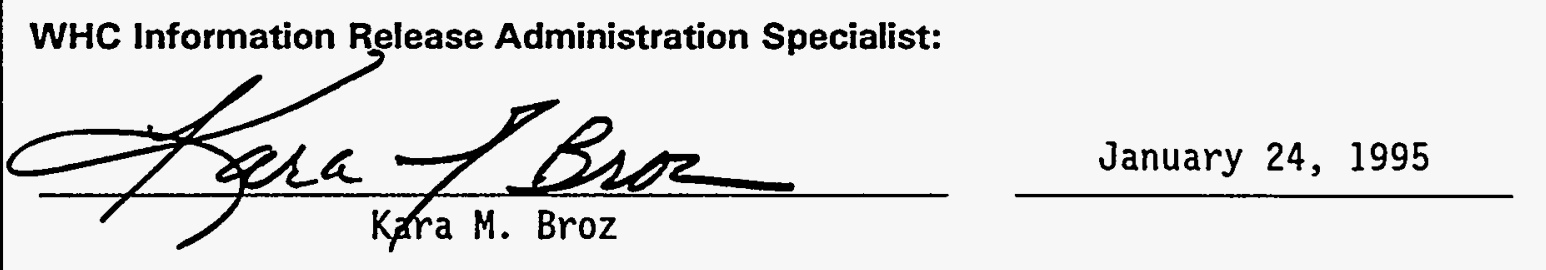

TRADEMARK DISCLAIMER. Reference herein to any specific commercial product, process, or service by trade name, trademark, manufacturer, or otherwise, does not necessarily constitute or imply its endorsement, recomendation, or favoring by the United States Government or any agency thereof or its contractors or subcontractors.

This report has been reproduced from the best available copy. Available in paper copy and microfiche. Printed in the United States of America. Available to the U.S. Department of Energy and its contractors from:

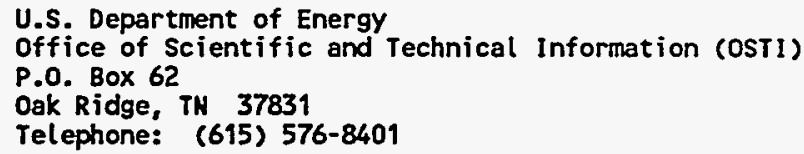

Available to the public from:

U.S. Department of Commerce

National Technical Information Service (NTIS)

5285 Port Royal Road

Springfield, VA 22161

Telephone: (703) 487-4650 


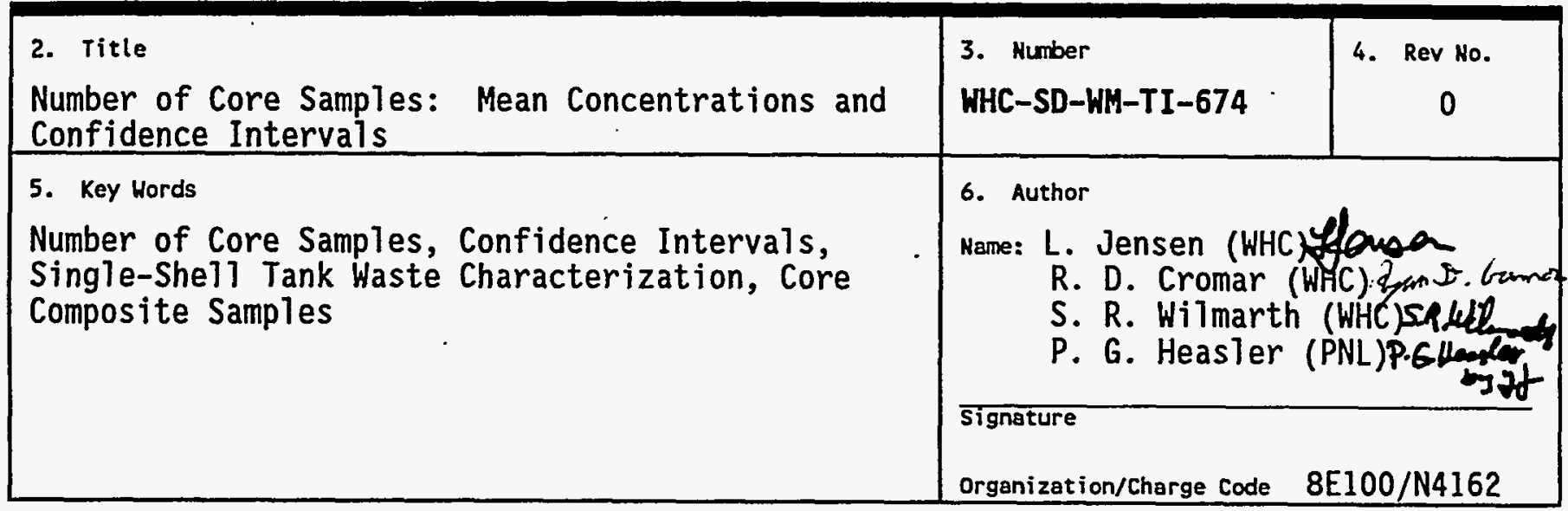

\section{Abstract}

This document provides estimates of how well the mean concentration of analytes are known as a function of the number of core samples, the number of composite samples, and the number of replicate analyses. The results are based upon core composite data from nine single-shell tanks. The results can be used to determine the number of core samples needed to "characterize" the waste in similar tanks.

\section{DISCLAIMER}

This report was prepared as an account of work sponsored by an agency of the United States Government. Neither the United States Government nor any agency thereof, nor any of their employees, makes any warranty, express or implied, or assumes any legal liability or responsibility for the accuracy, completeness, or usefulness of any information, apparatus, product, or process disclosed, or represents that its use would not infringe privately owned rights. Reference herein to any specific commercial product, process, or service by trade name, trademark, manufacturer, or otherwise does not necessarily constitute or imply its endorsement, recommendation, or favoring by the United States Government or any agency thereof. The views and opinions of authors expressed herein do not necessarily state or reflect those of the United States Government or any agency thereof.

\section{RELEASE STAMP

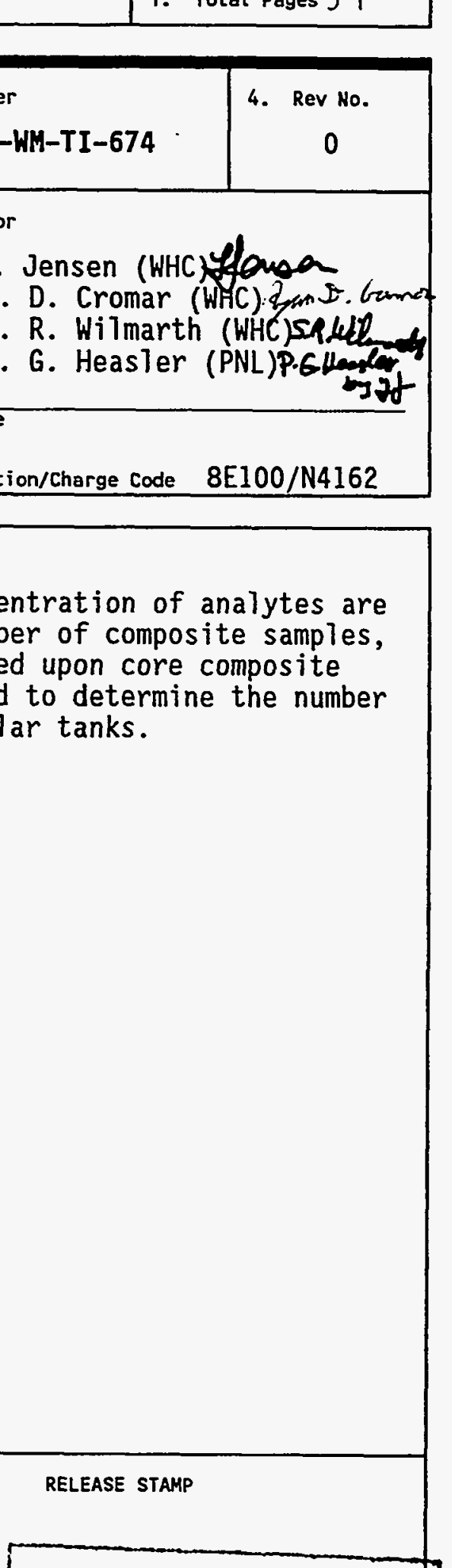

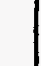


WHC-SD-WM-TI-674, Rev. 0

\title{
NUMBER OF CORE SAMPLES: MEAN CONCENTRATIONS \\ AND CONFIDENCE INTERVALS
}

January 1995

\author{
Westinghouse Hanford Company \\ L. Jensen \\ R. D. Cromar \\ S. R. Wilmarth \\ Pacific Northwest Laboratories \\ P. G. Heasler
}

Westinghouse Hanford Company
Richland, Washington 
WHC-SD-WM-TI-674, Rev. 0

This page intentionally left blank. 
WHC-SD-WM-TI-674, Rev. 0

\section{CONTENTS}

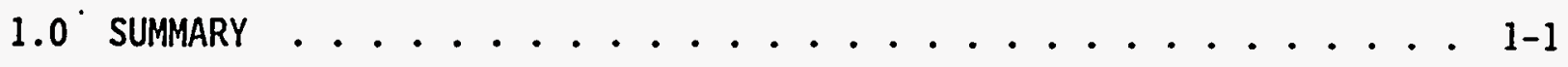

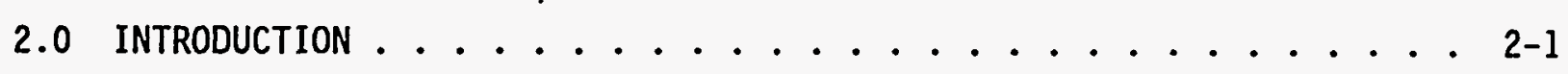

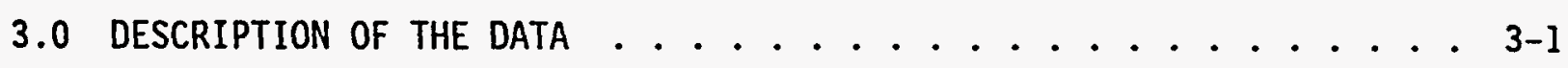

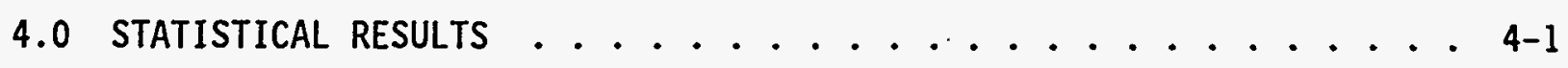

5.0 NUMBER OF OBSERVATIONS $. \ldots \ldots \ldots \ldots . \ldots . \ldots . \ldots$

5.1 CHANGE IN RELATIVE HALF-HIDTH $\ldots \ldots \ldots \ldots \ldots \ldots$

5.2 NUMBER OF CORE SAMPLES $\ldots \ldots \ldots \ldots \ldots \ldots \ldots$

6.0 CONCLUSION .......................... 6- .

7.0 REFERENCES ...........................

\section{APPENDIX}

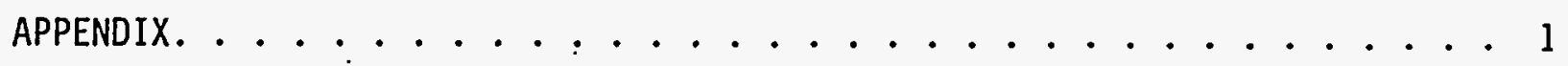


WHC-SD-WM-TI-674, Rev. 0

\section{LIST OF TABLES}

3-1 Number of Observations Per Tank . . . . . . . . . . . . 3-1

5-1 Relative Half-Width of $95 \%$ Confidence Intervals on the Mean (BX-107) ............... . . 5-1

5-2 . All Data, Percent of Analytes with 50\% RHW .......... . 5-2

A-1 Predicted Number of Core Samples Required for a Specified Half-Width of a 95\% Confidence Interval in the Mean for BX-107 . . 4

A-2 Predicted Number of Core Samples Required for a Specified Half-Width of a 95\% Confidence Interval in the Mean for C-109 . . . 8

A-3 Predicted Number of Core Samples Required for a Specified Half-Width of a 95\% Confidence Interval in the Mean for C-110 . . . 11

A-4 Predicted Number of Core Samples Required for a Specified Half-Width of a $95 \%$ Confidence Interval in the Mean for C-112 . . 15

A-5 Predicted Number of Core Samples Required for a Specified Half-Width of a 95\% Confidence Interval in the Mean for S-104 . . 18

A-6 Predicted Number of Core Samples Required for a Specified Half-Width of a 95\% Confidence Interval in the Mean for T-104 . . . 21

A-7 Predicted Number of Core Samples Required for a Specified Half-Width of a 95\% Confidence Interval in the Mean for T-105 . . 25

A-8 Predicted Number of Core Samples Required for a Specified Half-Width of a 95\% Confidence Interval in the Mean for T-107 . . . 29

A-9 Predicted Number of Core Samples Required for a Specified Half-Width of a 95\% Confidence Interval in the Mean for T-111. . . 
WHC-SD-WM-TI-674, Rev. 0

\section{LIST OF FIGURES}

5-1 Al1 Data, Number of Cores Needed to Achieve Desired Accuracy . . . 5-3

A-1 BX-107, Number of Cores Needed to Achieve Desired Accuracy . . . . 3

A-2 C-109, Number of Cores Needed to Achieve Desired Accuracy . . . . . 7

A-3 C-110, Number of Cores Needed to Achieve Desired Accuracy . . . . . 10

A-4 C-112, Number of Cores Needed to Achieve Desired Accuracy . . . . . 14

A-5 S-104, Number of Cores Needed to Achieve Desired Accuracy . . . . 17

A-6 T-104, Number of Cores Needed to Achieve Desired Accuracy . . . . 20

A-7 T-105, Number of Cores Needed to Achieve Desired Accuracy . . . . . 24

A-8 T-107, Number of Cores Needed to Achieve Desired Accuracy . . . . . 28

A-9 T-111, Number of Cores Needed to Achieve Desired Accuracy . . . . 32 


\section{LIST OF TERMS}

$\begin{array}{ll}\text { CI } & \text { confidence interval } \\ \text { Dir. } & \text { direct } \\ \text { Fluor. } & \text { fluorometric } \\ \text { GEA } & \text { gamma energy analysis } \\ \text { HW } & \text { half-width } \\ \text { IC } & \text { ion chromatography } \\ \text { IC.W. } & \text { ion chromatography of a water leached sample } \\ \text { ICP } & \text { inductively coupled plasma } \\ \text { ICP.a. } & \text { inductively coupled plasma analysis of an acid digested sample } \\ \text { ICP.f. } & \text { inductively coupled plasma analysis of a fusion digested sample } \\ \text { ICP.W. } & \text { inductively coupled plasma analysis of a water leached sample } \\ \text { KOH/Ni } & \text { Potassium Hydroxide/Nickel } \\ \text { RHW } & \text { relative half-width } \\ \text { RS } & \text { residual solids } \\ \text { SpeC.W. } & \text { spectroscopic method of a water leached sample } \\ \text { TA } & \text { total beta } \\ \text { TB } & \text { total alpha } \\ \text { TDS } & \text { total dissolved solids } \\ \text { TGA } & \text { thermal gravimetric analysis } \\ \text { TIC } & \text { total inorganic carbon } \\ \text { TOC } & \text { total organic carbon } \\ \mu \mathrm{g} / g & \text { micrograms per gram } \\ \mu C i / g & \text { microcuries per gram }\end{array}$


WHC-SD-WM-TI-674, Rev. 0

\section{NUMBER OF CORE SAMPLES: MEAN CONCENTRATIONS \\ AND CONFIDENCE INTERVALS}

\subsection{SUMMARY}

This document provides estimates of how well the mean concentrations of analytes are known as a function of the number of core samples, composite samples, and replicate analyses. The estimates are based upon core composite data from nine recently sampled single-shell tanks. The results can be used when determining the number of core samples needed to "characterize" the waste from similar single-shell tanks.

A standard way of expressing uncertainty in the estimate of a mean is with a $95 \%$ confidence interval (CI). We investigate how the width of a $95 \%$ CI on the mean concentration decreases as the number of observations increase. Specifically, the tables and figures show how the "relative half-width" (RHW) of a 95\% CI decreases as the number of core samples increases. The RHW of a CI is a unit-less measure of uncertainty.

The general conclusions are as follows.

- The RHW decreases dramatically as the number of core samples is increased. The decrease is much smaller when the number of composite samples or the number of replicate analyses are increased.

- If the mean concentration of an analyte needs to be estimated with a "small" RHW, then a "large" number of core samples is required.

The estimated number of core samples given in the tables and figures were determined by specifying different sizes of the RHW. Four nominal sizes were examined: $10 \%, 25 \%, 50 \%$, and $100 \%$ of the observed mean concentration.

For a majority of analytes the number of core samples required to achieve an accuracy within $10 \%$ of the mean concentration is extremely 1 arge. In many cases, however, two or three core samples is sufficient to achieve a RHW of approximately 50 to 100\%. Because many of the analytes in the data have small concentrations, this level of accuracy may be satisfactory for some applications. 
WHC-SD-WM-TI-674, Rev. 0

This page intentionally left blank. 


\subsection{INTRODUCTION}

A statistical analysis of waste characterization data from nine single-she11 tanks (BX-107, C-109, C-110, C-112, S-104, T-104, T-105, T-107, and T-111) has been completed. The results of the statistical analyses, based upon analysis of variance methods applied to core composite data, are given in the references.

Core samples consist of several disjoint segments which represent, from top to bottom, the waste in the tank. Core composite samples are made by homogenizing individual segments and then combining material from these segments into a single sample. In some cases two core composite samples are created from each core.

When core composite samples are formed, vertical variability in the waste is removed. Core composite samples are used to estimate analyte mean concentrations and to predict tank inventory. 
WHC-SD-WM-TI-674, Rev. 0

This page intentionally left blank. 
HHC-SD-WM-TI-674, Rev. 0

\subsection{DESCRIPTION OF THE DATA}

Table 3-1 gives the number of core samples and the number of composite samples per core for each of the nine tanks. Two replicate analyses were done on each core composite.

Table 3-1. Number of Observations Per Tank.

\begin{tabular}{|c|c|c|c|c|}
\hline Tank & $\begin{array}{c}\text { Number of core } \\
\text { samples }\end{array}$ & $\begin{array}{c}\text { Number of } \\
\text { composite samples }\end{array}$ & $\begin{array}{c}\text { Number of } \\
\text { observations } \\
\text { per analyte }\end{array}$ & $\begin{array}{c}\text { Number of } \\
\text { analytes }\end{array}$ \\
\hline \hline BX-107 & 2 & 2 & 8 & 74 \\
\hline C-109 & 3 & 1 & 6 & 33 \\
\hline $\mathrm{C}-110$ & 3 & 2 & 12 & 79 \\
\hline $\mathrm{C}-112$ & 3 & 1 & 6 & 33 \\
\hline $\mathrm{S}-104$ & 3 & 2 & 12 & 63 \\
\hline $\mathrm{T}-104$ & 2 & 2 & 8 & 80 \\
\hline $\mathrm{T}-105$ & 2 & 1 & 4 & 71 \\
\hline$T-107$ & 2 & 1 & 4 & 74 \\
\hline$T-111$ & 2 & 2 & 8 & 85 \\
\hline
\end{tabular}

The chemical analyses performed on the samples were the following:

- inductively coupled plasma (ICP) analysis of an acid digested sample (ICP.a)

- ICP of a potassium hydroxide/nickel (KOH/Ni) fused sample (ICP.f)

- ICP analysis of a water leached sample (ICP.W)

- ion chromatography (IC) of a water leached sample (IC.W)

- radiochemistry.

The tables in the appendix identify results using the above notation. For example, ICP.a.AT refers to the AT concentration from an ICP analysis of an acid digested sample. 
WHC-SD-WM-TI-674, Rev. 0

This page intentionally left blank. 


\subsection{STATISTICAL RESULTS}

Analysis of variance methods were used to estimate three variance components from the core composite data: the spatial variability, $\hat{\sigma}^{2}(S)$; the compositing variability, $\hat{\sigma}^{2}(C)$; and the analytical measurement variability, $\hat{\sigma}^{2}(A)$. Compositing variability can only be estimated from data with more than one composite sample per core. Tables of the variance components are given in the references.

The half-width of a CI can be calculated using Equation (1). The half-width is a measure of how well a mean estimate is known. A small half-width indicates that the uncertainty associated with a mean concentration estimate is small, a large half-width indicates that the uncertainty is large.

$$
H W(a, b, n)=t_{(a-1)} \sqrt{\frac{\hat{\sigma}^{2}(S)}{a}+\frac{\hat{\sigma}^{2}(C)}{a b}+\frac{\hat{\sigma}^{2}(A)}{a b n}}
$$

Using Equation (1), the number of core samples (a), the number of composite samples (b), and the number of replicate analyses $(n)$ can be varied to study how the width of the CI changes.

The term $t_{(a-1)}$ is a value from Student's $t$ distribution with a-l degrees of freedom. Student's $t$ distribution is used to account for the uncertainty in the estimates of the variances.

The numbers $a, b$, and $n$ are in the denominators of Equation (1), consequently the terms $\hat{\sigma}^{2}(S) / a, \hat{\sigma}^{2}(C) / a b$, and $\hat{\sigma}^{2}(A) / a b n$ decrease as the numbers $a, b$, and $n$ increase. The number of core samples, $a$, has the most influence on the width of the CI because it is in all three terms. The values from Student's $t_{(a-1)}$ distribution also depends on the number of core samples. For a two sided $95 \% \mathrm{CI}$, the appropriate quantile points with one, two, and three degrees of freedom are 12.706, 4.303, and 3.182.

The RHW, in \%, of a CI is the half-width divided by the mean analyte concentration $\bar{y}$. The formula for the RHW of a CI is given in Equation (2),

$$
\operatorname{RHW}(a, b, n)=H W(a, b, n) * 100 / \bar{y} .
$$

In this document, the RHW is used to determine how the width of the CI decreases as the number of core samples, composite samples, and replicate analyses increase. 
WHC-SD-WM-TI-674, Rev. 0

This page intentionally left blank. 


\subsection{NUMBER OF OBSERVATIONS}

\subsection{CHANGE IN RELATIVE HALF-HIDTH}

The results given in this section were obtained by varying values of the numbers $a, b$, and $n$. The values $\hat{\sigma}^{2}(S), \hat{\sigma}^{2}(C), \hat{\sigma}^{2}(A)$, and $\bar{y}$ were obtained from the sampling data from a given tank. The values of these four parameters can be found in the references.

For several analytes in BX-107, Table 5-1 shows how dramatically the CI half-width decreases as the number of core samples is increased. The first column in Table 5-1 gives the analyte using the notation of Section 3.0. The second column gives the mean concentration estimate, $\bar{y}$, for the analyte in $\mu \mathrm{g} / \mathrm{g}$ (parts per million). The remaining columns report the RHW for different combinations of the numbers $(a, b, n)$.

Table 5-1. Relative Half-Width of 95\% Confidence Intervals on the Mean $(B X-107)$.

\begin{tabular}{|c|c|c|c|c|c|c|c|c|}
\hline & Mean & & . & & $(0, b, n) \star$ & & & \\
\hline Analyte & $\mathrm{molo}$ & $(2,2,2) *$ & $(3,2,2)$ & $(4,2,2)$ & $(2,3,2)$ & $(2,4,2)$ & $(2,2,3)$ & $(2,2,4)$ \\
\hline ICP.a.AI & $1.42 E+04$ & $191 \%$ & $53 \%$ & $34 \%$ & $191 \%$ & $191 \%$ & $191 \%$ & $191 \%$ \\
\hline ICP.o.Na & $1.02 E+05$ & $11 \%$ & $3 \%$ & $2 \%$ & $9 \%$ & $8 \%$ & $10 \%$ & $10 \%$ \\
\hline ICP.f.A| & $1.43 E+0.4$ & $122 \%$ & $34 \%$ & $22 \%$ & $112 \%$ & $107 \%$ & $121 \%$ & $120 \%$ \\
\hline ICP.t.Na & $1.00 E+05$ & $24 \%$ & $7 \%$ & $4 \%$ & $20 \%$ & $17 \%$ & $24 \%$ & $24 \%$ \\
\hline$|C P . w . A|$ & $1.34 E+02$ & $463 \%$ & $128 \%$ & $82 \%$ & $378 \%$ & $328 \%$ & $453 \%$ & $448 \%$ \\
\hline ICP.W.Na & $6.81 E+03$ & $148 \%$ & $41 \%$ & $26 \%$ & $130 \%$ & $120 \%$ & $130 \%$ & $120 \%$ \\
\hline IC.w.F & $9.19 E+03$ & $100 \%$ & $28 \%$ & $18 \%$ & $92 \%$ & $87 \%$ & $100 \%$ & $100 \%$ \\
\hline IC.w.Cl & $1.14 E+03$ & $36 \%$ & $10 \%$ & $6 \%$ & $30 \%$ & $26 \%$ & $35 \%$ & $35 \%$ \\
\hline IC.w.PO4 & $1.42 E+0.4$ & $39 \%$ & $11 \%$ & $7 \%$ & $37 \%$ & $36 \%$ & $39 \%$ & $39 \%$ \\
\hline IC.w.SO4 & $1.34 E+04$ & $70 \%$ & $19 \%$ & $12 \%$ & $69 \%$ & $69 \%$ & $70 \%$ & $70 \%$ \\
\hline
\end{tabular}

$\star: a=$ number of core samples, $b=$ number of composite samples, $n=$ number of replicate analyses. analyses.

\#: Observed number of core samples, composite samples, and replicate

The analyte ICP.a.Al is given in the first row of Table 5-1. The mean concentration of ICP.a.AT is $14,200 \mu \mathrm{g} / \mathrm{g}(1.42 \%)$. The RHW for two core samples, two composite samples, and two replicate analysis, $(2,2,2)$, is $191 \%$. When the number of core samples is increased from 2 to $3,(3,2,2)$, the RHW decreases to $53 \%$. Increasing the number of core samples to four, $(4,2,2)$, decreases the RHW to $34 \%$. Changes in the number of composite samples, $b$, or the number of replicate analysis, $n$, have a negligible influence on the RHW. Similar results are observed for the other analytes in BX-107, and for each of the nine tanks in this study. 


\subsection{NUMBER OF CORE SAMPLES}

The results in this section were obtained by determining the number of core samples so that the RHW is $10 \%, 25 \%, 50 \%$, and $100 \%$ of the mean. Tables A-1 to A-9, in the appendix, contain the estimates. Each of these nine tables give the number of core samples on an analyte by analyte basis.

For each of the nine tanks, Figures $A-1$ to $A-9$, in the appendix, summarize the results for all of the analytes in a tank. Figure 5-1 combines the results from each of the individual figures.

In the figures, the number of analytes measured were divided into six groups: those that required two cores, three cores, four cores, 5 to 9 cores, 10 to 19 cores, and $20+$ cores.

For a RHW of $50 \%$, Table 5-2 gives the percent of the total number of analytes (592) which fall into the six groups. In Figure 5-1, the chart labeled "50 Percent of the Mean" displays the same information.

Table 5-2. Al1 Data, Percent of Analytes with $50 \%$ RHW.

\begin{tabular}{|c||c|c|}
\hline Core samples & \% of Analytes & Cumulative \% \\
\hline 2 & $14 \%$ & $14 \%$ \\
\hline 3 & $34 \%$ & $48 \%$ \\
\hline 4 & $14 \%$ & $62 \%$ \\
\hline 5 to 9 & $24 \%$ & $86 \%$ \\
\hline 10 to 19 & $10 \%$ & $96 \%$ \\
\hline $20+$ & $4 \%$ & $100 \%$ \\
\hline
\end{tabular}

For example, if three core samples are obtained, then $34 \%$ of the analytes will have a $95 \%$ CI on the mean with a RHW of $50 \%$. Note that if three core samples are obtained, then two core samples are also obtained. This means that with three core samples, $48 \%(14 \%+34 \%)$ of the analytes will have a $95 \%$ CI on the mean with a RHW of less than or equal to $50 \%$.

A conclusion from the figures is that if the mean concentration is to be estimated so that the width of a $95 \%$ CI is smal1, then a large number of core samples are required. From Figure 5-1, it is evident that if three core samples are obtained, then the half-width of the $95 \%$ CI is within $100 \%$ of the mean for 70 to $80 \%$ of the analytes, or within $50 \%$ of the mean for 40 to $50 \%$ of the analytes.

With the two cores samples taken from BX-107, T-104, T-105, T-107, and T-11l, the observed half-width of the $95 \%$ CI was within $100 \%$ of the mean for $33 \%, 69 \%, 4 \%, 20 \%$, and $39 \%$ of the analytes, respective $7 y$. Based on the three cores samples taken from $\mathrm{C}-109, \mathrm{C}-110, \mathrm{C}-112$, and $\mathrm{S}-104$, the observed half-width of the $95 \%$ CI was within $100 \%$ of the mean for $51 \%, 66 \%, 46 \%$, and $70 \%$ of the analytes, respectively. Note the change in the percent of the analytes within the observed CIs as the number of core samples increases from two to three. 
Figure 5-1. All Data, Number of Cores Needed to Achieve Desired Accuracy.

10 PERCENT OF THE MEAN

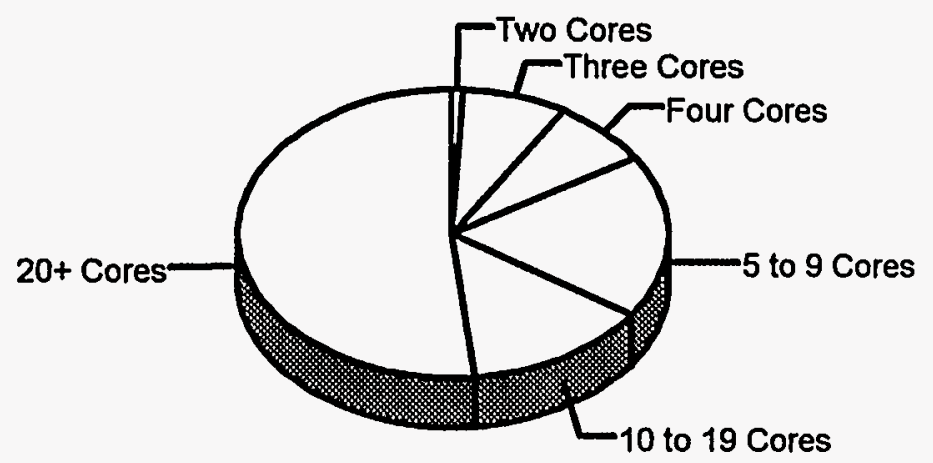

w

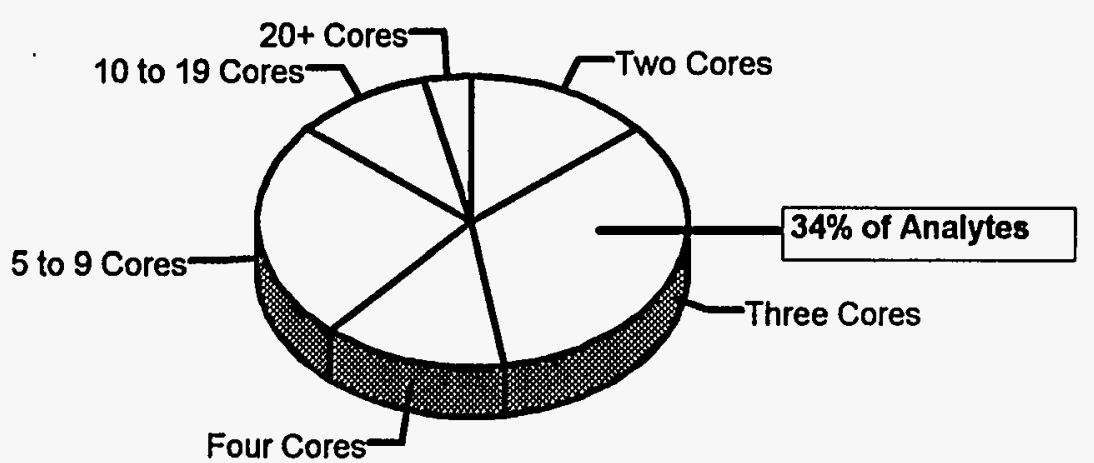

.25 PERCENT OF THE MEAN

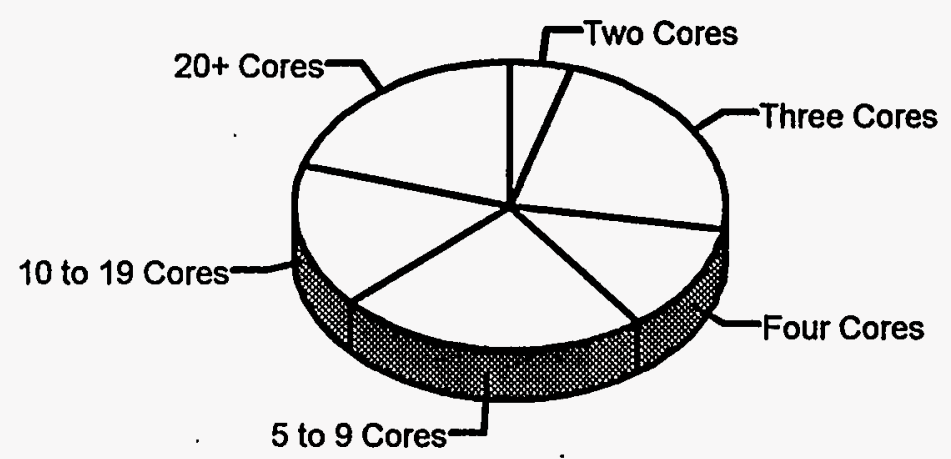

100 PERCENT OF THE MEAN

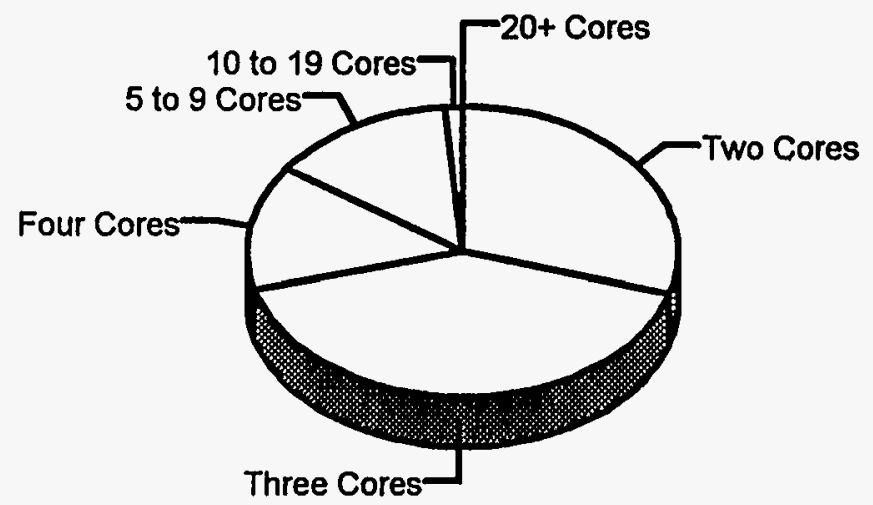


WHC-SD-WM-TI-674, Rev. 0

This page intentionally left blank. 


\subsection{CONCLUSION}

The tables given in this document can be used to determine the number of core samples needed to "characterize" the waste in unsampled single-shell tanks. Two steps must be followed.

- The desired accuracy for the mean concentration of an analyte must be expressed in terms of a bound on the width of a confidence interval.

- The type of waste in an unsampled single-shell tank must be similar to the waste in one of the nine sampled tanks.

The number of core samples given in the nine tables are to be used to estimate the mean concentration of the analytes in the waste. These numbers are not the number of core samples needed to satisfy complex safety criteria.

In this document the number of core samples required to achieve RHW's of $10,25,50$, and $100 \%$ of the mean, were calculated on a tank by tank basis. No assumptions about the similarity or differences between tanks were used in the calculations. At this time the validity of pooling data from groups of similar tanks is unknown. On an analyte by analyte basis, a statistical comparison between the nine tanks in this study is being performed. The results of this comparison will tell if data from similar tanks can be combined. If data from multiple tanks can be used when calculating estimates, the number of core samples required for a given application could be reduced. 
WHC-SD-WM-TI-674, Rev. 0

This page intentionally left blank.

6-2 


\subsection{REFERENCES}

Jensen, L., and K. M. Remund, 1994, Statistical Characterization Report for Single-She77 Tank 241-BX-107, WHC-SD-WM-TI-603, Rev. 0, Westinghouse Hanford Company, Richland, Washington.

Jensen, L., and K. M. Remund, 1994, Statistical Characterization Report for Single-She11 Tank 241-C-110, WHC-SD-WM-TI-585, Rev. 0, Westinghouse Hanford Company, Richland, Washington.

Jensen, L., R. D. Cromar, and S. R. Wilmarth, 1994, Statistical Characterization Report for Single-She17 Tank 241-S-104, WHC-SD-WM-TI-652, Rev. 0, Westinghouse Hanford Company, Richland, Washington.

Jensen, L., R. D. Cromar, and S. R. Wilmarth, 1994, Statistical Characterization Report for Single-She17 Tank 241-T-104, WHC-SD-WM-TI-658, Rev. 0, Hestinghouse Hanford Company, Richland, Washington.

Jensen, L., R. D. Cromar, and S. R. Wilmarth, 1994, Statistical Characterization Report for Single-She71 Tank 241-T-105, WHC-SD-WM-TI-653, Rev. 0, Westinghouse Hanford Company, Richl and, Washington.

Jensen, L., R. D. Cromar, and S. R. Wilmarth, 1994, Statistical Characterization Report for Single-Shell Tank 241-T-107, WHC-SD-WM-TI-645, Rev. 0, Westinghouse Hanford Company, Richland, Washington.

Jensen, L., R. D. Cromar, and S. R. Wilmarth, 1994, Statistical Characterization Report for Single-Shell Tank 241-T-111, WHC-SD-WM-TI-650, Rev. 0, Westinghouse Hanford Company, Richland, Washington.

Simpson, B. C., G. L. Borsheim, and L. Jensen, 1993, Tank Characterization Report: Tank 241-C-109, WHC-EP-0668, Westinghouse Hanford Company, Richland, Washington.

Simpson, B. C., G. L. Borsheim, and L. Jensen, 1993, Tank Characterization Report: Tank 241-C-112, WHC-EP-0640, Westinghouse Hanford Company, Richland, Hashington. 
WHC-SD-WM-TI-674, Rev. 0

This page intentionally left blank. 
WHC-SD-WM-TI-674, Rev. 0

\section{APPENDIX}

FIGURES AND TABLES 
WHC-SD-WM-TI-674, Rev. 0

This page intentionally left blank. 
Figure A-1. BX-107, Number of Cores Needed to Achieve Desired Accuracy.

10 PERCENT OF THE MEAN

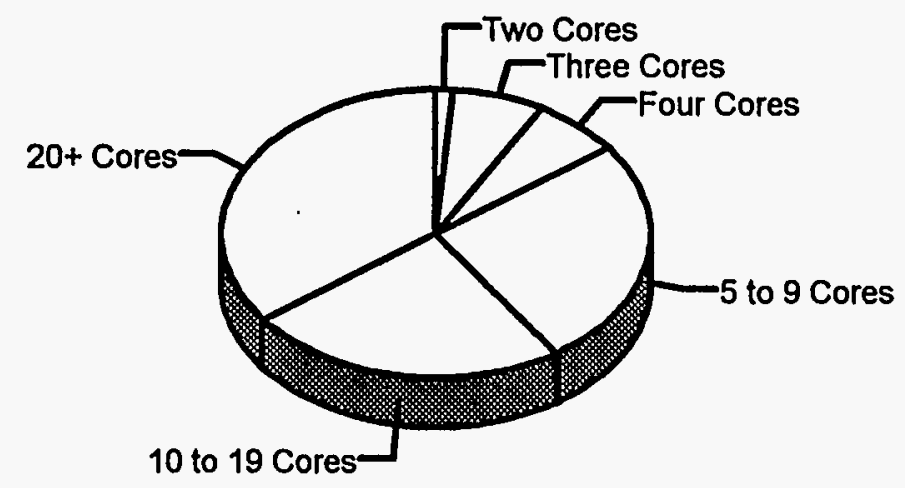

$\omega$ 25 PERCENT OF THE MEAN

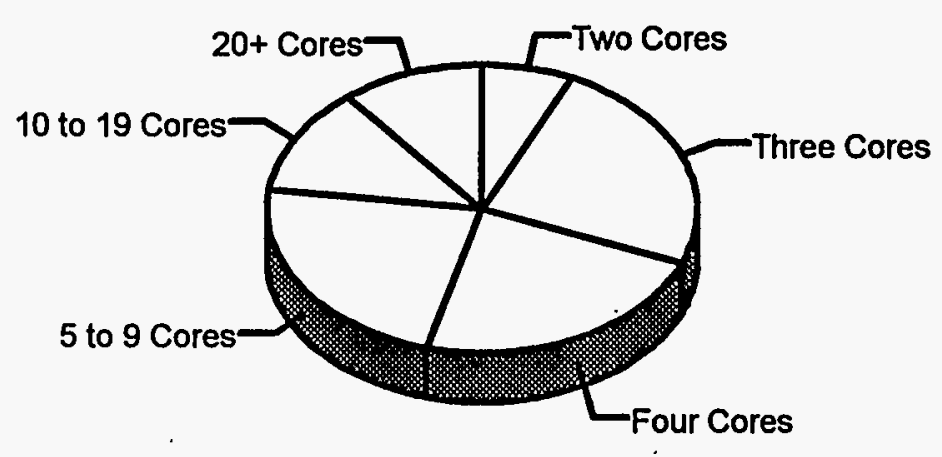

100 PERCENT OF THE MEAN

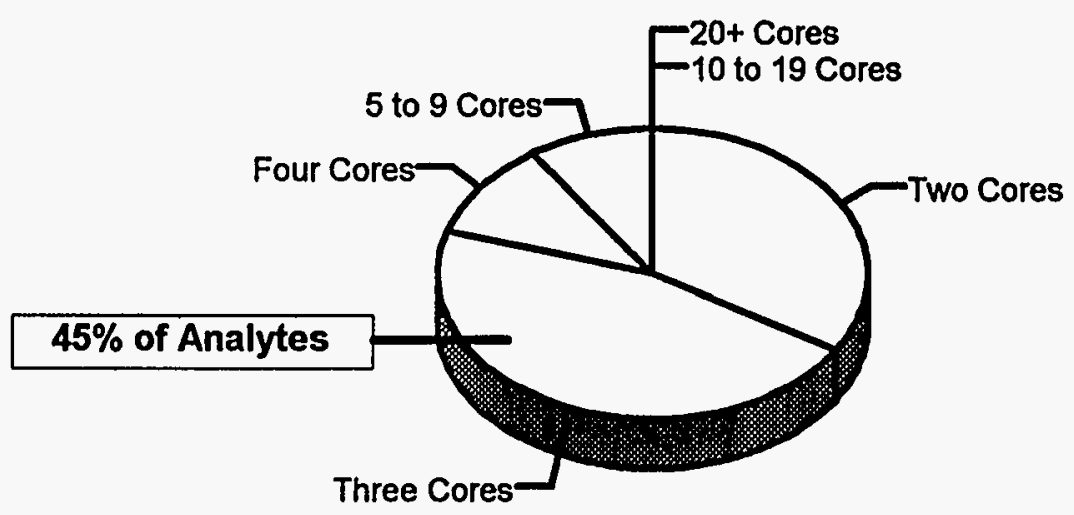

Three Cores

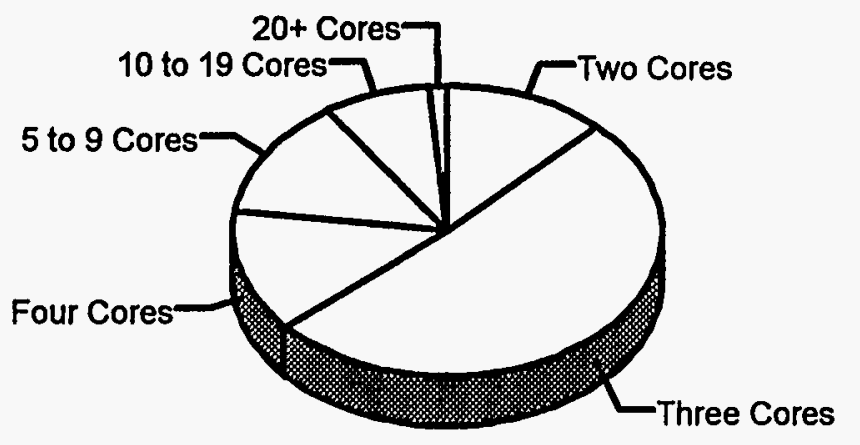


WHC-SD-WM-TI-674, Rev. 0

Table A-1. Predicted Number of Core Samples Required for a Specified Half-Width of a 95\% Confidence Interval in the Mean for BX-107.

(sheet 1 of 3)

\begin{tabular}{|c|c|c|c|c|c|}
\hline \multirow[b]{2}{*}{ Analyte } & \multirow{2}{*}{$\frac{\text { Moan }}{\mu \mathrm{g} / \mathrm{g} \text { or } \mu \mathrm{Ci} / \mathrm{g}}$} & \multicolumn{4}{|c|}{ Half-Width of Confidence Interval as $\%$ of Mean } \\
\hline & & $10 \%$ & $25 \%$ & $50 \%$ & $100 \%$ \\
\hline ICP.a.AI & $1.42 E+04$ & 20 & 6 & 4 & 3 \\
\hline ICP.a.B & $4.71 E+01$ & 31 & 7 & 4 & 3 \\
\hline ICP.a.Ba & $8.18 E+\infty 0$ & 33 & 8 & 4 & 3 \\
\hline ICP.a.Bi & $2.42 E+04$ & 11 & 4 & 3 & 3 \\
\hline ICP.a.Ca & $1.04 E+03$ & 123 & 22 & 8 & 4 \\
\hline 1CP.a.Ce & $1.78 E+02$ & 11 & 4 & 3 & 3 \\
\hline ICP.a.Cr & $9.58 E+02$ & 10 & 4 & 3 & 3 \\
\hline ICP.A.Cu & $4.28 E+01$ & 263 & 45 & 13 & 6 \\
\hline ICP.a.Fe & $1.10 E+04$ & 19 & 6 & 4 & 3 \\
\hline ICP.a.K & $2.63 E+02$ & 14 & 5 & 3 & 3 \\
\hline ICP.a.Mg & $1.59 E+02$ & 9 & 4 & 3 & 3 \\
\hline ICP.a.Mn & $3.98 E+01$ & 17 & 5 & 3 & 3 \\
\hline ICP.a.Na & $1.02 E+05$ & 3 & 2 & 2 & 2 \\
\hline ICP.a.Ni & $1.22 E+01$ & 16 & 5 & 3 & 3 \\
\hline ICP.a.P & $2.31 E+0.4$ & 12 & 4 & 3 & 3 \\
\hline ICP.a.Pb & $6.28 E+01$ & 24 & 6 & 4 & 3 \\
\hline ICP.A.S & $4.57 E+03$ & 7 & 3 & 3 & 2 \\
\hline ICP.a.Se & $3.26 E+02$ & 10 & 4 & 3 & 3 \\
\hline ICP.s.Si & $1.66 \mathrm{E}+03$ & 4 & 3 & 2 & 2 \\
\hline ICP.a.Sr & $1.67 E+02$ & 6 & 3 & 3 & 2 \\
\hline ICP.a.TI & $3.86 E+\infty 0$ & 14 & 5 & 3 & 3 \\
\hline ICP.a.Zn & $5.95 E+01$ & 44 & 10 & 5 & 3 \\
\hline ICP.a.Zr & $9.62 E+01$ & 5 & 3 & 3 & 2 \\
\hline [CP.t.A] & $1.43 E+04$ & 10 & 4 & 3 & 3 \\
\hline ICP.f.Bi & $2.23 E+04$ & 9 & 4 & 3 & 3 \\
\hline ICP.f.Ca & $3.96 E+02$ & 22 & 6 & 4 & 3 \\
\hline ICP.t.Cr & $9.68 E+02$ & 6 & 3 & 3 & 2 \\
\hline ICP.f.Cu & $5.16 E+01$ & 94 & 18 & 7 & 4 \\
\hline ICP.f.Fe & $1.11 E+04$ & 11 & 4 & 3 & 3 \\
\hline ICP.f.Mg & $1.12 E+02$ & 11 & 4 & 3 & 3 \\
\hline
\end{tabular}


Table A-1. Predicted Number of Core Samples Required for a Specified Half-Width of a 95\% Confidence Interval in the Mean for BX-107.

\begin{tabular}{|c|c|c|c|c|c|}
\hline & Moan & \multicolumn{4}{|c|}{ Half-Width of Confidence Interval as $\%$ of Mean } \\
\hline Analyto & $\mu \mathrm{g} / \mathrm{g}$ or $\mathrm{\mu CH} / \mathrm{s}$ & $10 \%$ & $25 \%$ & $50 \%$ & $100 \%$ \\
\hline ICP.f.Mn & $6.46 E+01$ & 10 & 4 & 3 & $\mathbf{3}$ \\
\hline ICP.f.Na & $1.00 E+05$ & $\mathbf{3}$ & 2 & 2 & 2 \\
\hline ICP.f.NI & $5.68 E+03$ & 99 & 18 & 7 & 4 \\
\hline ICP.f.P & $2.34 E+04$ & 6 & 3 & 3 & 2 \\
\hline ICP.f.S & 4.44E+03 & 7 & 3 & 3 & 2 \\
\hline ICP.t.Si & $6.78 E+03$ & 7 & 3 & 3 & 2 \\
\hline ICP.f.Sr & $1.68 E+02$ & 4 & 3 & 3 & 2 \\
\hline ICP.f.Zn & $8.33 E+01$ & 55 & 11 & 5 & 3 \\
\hline ICP.f.Zr & $1.36 E+02$ & 33 & 8 & 4 & 3 \\
\hline ICP.w.Al & $1.34 E+02$ & 105 & 19 & 7 & 4 \\
\hline ICP.W.B & $2.50 E+01$ & 16 & 5 & 3 & 3 \\
\hline ICP.w.Bi & $2.34 E+02$ & 280 & 47 & 14 & 6 \\
\hline ICP.w.Ca & $4.34 E+02$ & 367 & 61 & 18 & 7 \\
\hline ICP.w. Cr & $1.51 E+02$ & 4 & 3 & 3 & 2 \\
\hline ICP.w.Fo & $1.18 E+02$ & 273 & 46 & 14 & 6 \\
\hline ICP.w.K & $1.47 E+02$ & 6 & 3 & 3 & 2 \\
\hline ICP.w.Mg & $1.65 E+01$ & 231 & 39 & 12 & 5 \\
\hline ICP.w.Na & $6.81 E+04$ & 13 & 5 & 3 & 3 \\
\hline ICP.w.P & $4.79 E+03$ & 3 & 2 & 2 & 2 \\
\hline ICP.w.S & $4.43 E+03$ & 4 & 3 & 2 & 2 \\
\hline ICP.w.Si & $2.94 E+02$ & 83 & 16 & 6 & 4 \\
\hline ICP.W.Sr & $2.46 E+00$ & 95 & 18 & 7 & 4 \\
\hline ICP.w.Zn & $2.49 E+00$ & 413 & 69 & 19 & 7 \\
\hline IC.W.F & $9.19 E+03$ & 8 & 4 & 3 & 3 \\
\hline IC.W.Cl & $1.14 E+03$ & 3 & 3 & 2 & 2 \\
\hline IC.W.NO3 & $1.37 E+0.5$ & 6 & 3 & 3 & 2 \\
\hline IC.w.NO2 & $8.12 E+03$ & 71 & 14 & 6 & 4 \\
\hline IC.w.PO4 & $1.42 E+04$ & 4 & 3 & 2 & 2 \\
\hline IC.w.SO4 & $1.34 E+04$ & 5 & 3 & 3 & 2 \\
\hline Dir.\%TGA & 5.91E + 01 & 5 & 3 & 3 & 2 \\
\hline Dir.\%Water & $5.67 E+01$ & 3 & 2 & 2 & 2 \\
\hline
\end{tabular}


WHC-SD-WM-TI-674, Rev. 0

Table A-1. Predicted Number of Core Samples Required for a Specified Half-Width of a 95\% Confidence Interval in the Mean for BX-107. (sheet 3 of 3 )

\begin{tabular}{|c|c|c|c|c|c|}
\hline & Moan & \multicolumn{4}{|c|}{ Half-Width of Confidence Interval as $\%$ of Mean } \\
\hline Analyte & $\mu \mathrm{g} / \mathrm{g}$ or $\mu \mathrm{Ci} / \mathrm{g}$ & $10 \%$ & $25 \%$ & $50 \%$ & $100 \%$ \\
\hline Dir.CN & $2.49 E+\infty 0$ & 21 & 6 & 4 & 3 \\
\hline Spec.w.NO2 & $1.23 E+04$ & $\mathbf{5}$ & 3 & 3 & 2 \\
\hline pH & $9.71 E+\infty$ & 2 & 2 & 2 & 2 \\
\hline TIC & $1.16 E+03$ & 8 & 4 & 3 & 3 \\
\hline Fluor.U & $7.68 E+03$ & 434 & 72 & 20 & 7 \\
\hline TA & 9.63E-02 & 26 & 7 & 4 & 3 \\
\hline TB & $4.67 E+01$ & $\mathbf{8}$ & 4 & 3 & 3 \\
\hline GEA.Cs-137 & $1.74 E+01$ & 68 & 13 & 6 & 4 \\
\hline Pur-239/240 & $5.72 \mathrm{E}-02$ & 17 & 5 & 3 & 3 \\
\hline Am-241 & $1.30 \mathrm{E}-02$ & 7 & 4 & 3 & 2 \\
\hline Te-99 & 3.69E-02 & 10 & 4 & 3 & 3 \\
\hline Sr-90 & $9.87 E+00$ & 8 & 4 & 3 & 2 \\
\hline $\mathrm{H}-3$ & 5.77E-04 & 35 & 8 & 4 & 3 \\
\hline
\end{tabular}


Figure A-2. C-109, Number of Cores Needed to Achieve Desired Accuracy.

10 PERCENT OF THE MEAN

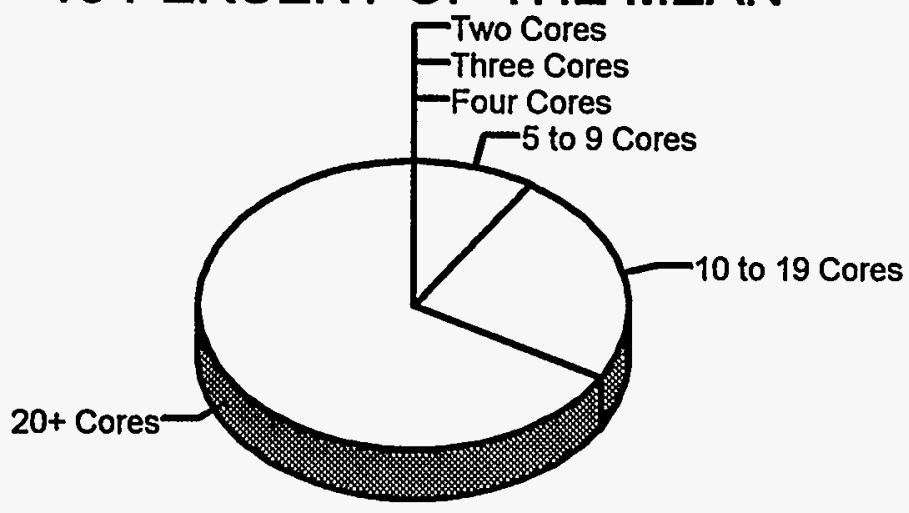

50 PERCENT OF THE MEAN

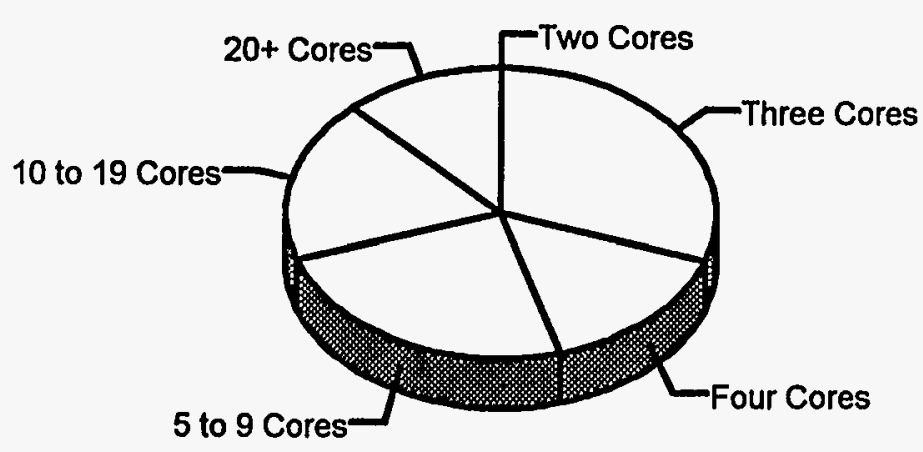

25 PERCENT OF THE MEAN

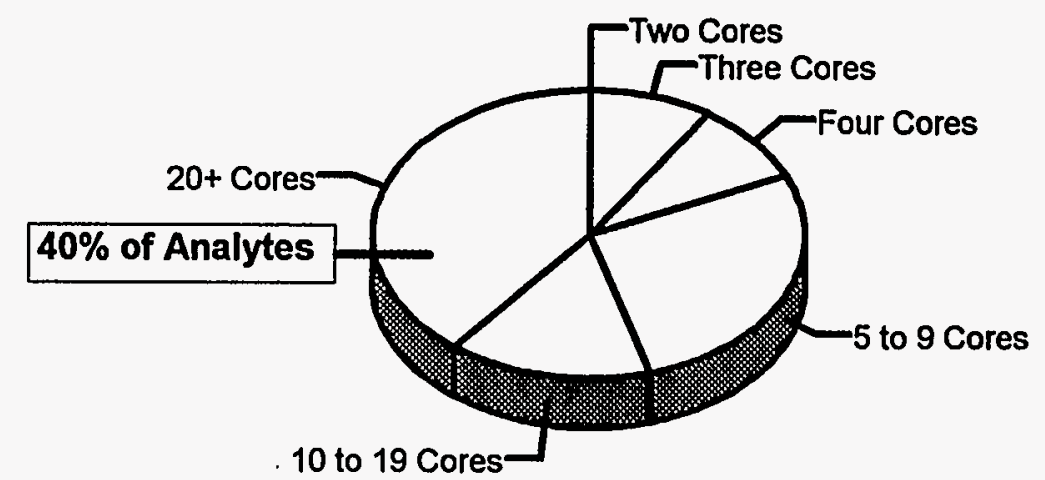

100 PERCENT OF THE MEAN

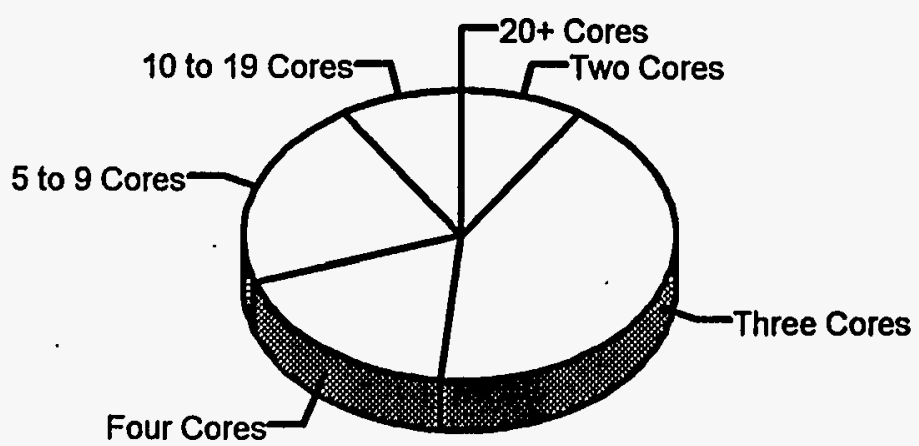


WHC-SD-WM-TI-674, Rev. 0

Table A-2. Predicted Number of Core Samples Required for a Specified Half-Width of a 95\% Confidence Interval in the Mean for C-109. (sheet 1 of 2 )

\begin{tabular}{|c|c|c|c|c|c|}
\hline \multirow[b]{2}{*}{ Analyte } & \multirow{2}{*}{$\frac{\text { Mean }}{\text { pro/g or } \mu \mathrm{Ci} / \mathrm{g}}$} & \multicolumn{4}{|c|}{ Half-Width of Confidence Interval as \% of Mean } \\
\hline & & $10 \%$ & $25 \%$ & $50 \%$ & $100 \%$ \\
\hline ICP.a.Al & $5.43 E+0.4$ & 231 & 39 & 12 & 5 \\
\hline ICP.a.Ca & $3.50 E+0.4$ & 36 & 8 & 4 & 3 \\
\hline ICP.a.Fe & $1.87 E+04$ & 133 & 24 & 8 & 4 \\
\hline ICP.a.Na & $8.36 E+04$ & 6 & 3 & 3 & 2 \\
\hline ICP.a.Ni & $1.40 E+0.4$ & 10 & 4 & 3 & 3 \\
\hline ICP.a.P & $1.83 E+04$ & 19 & 6 & 4 & 3 \\
\hline ICP.A.PD & $3.36 E+03$ & 705 & 115 & 31 & 10 \\
\hline ICP.a.U & $1.07 E+04$ & 68 & 13 & 6 & 4 \\
\hline ICP.f.AI & $8.40 E+04$ & 237 & 40 & 12 & 5 \\
\hline ICP.t.Ca & $1.91 E+04$ & 30 & 7 & 4 & 3 \\
\hline ICP.f.Fo & $1.77 E+04$ & 71 & 14 & 6 & 4 \\
\hline ICP.f.Na & 8.79E +04 & 10 & 4 & 3 & 3 \\
\hline ICP.t.P & $1.82 E+0.4$ & 14 & 5 & 3 & 3 \\
\hline ICP.t.Pb & $4.05 E+03$ & 490 & 81 & 22 & 8 \\
\hline ICP.f.U & $1.47 E+04$ & 186 & 32 & 10 & 5 \\
\hline ICP.w.Ca & $1.07 E+02$ & 154 & 27 & 9 & 4 \\
\hline ICP.w.Fo & $9.78 E+02$ & 11 & 4 & 3 & 3 \\
\hline ICP.w.Na & $7.04 E+04$ & 14 & 5 & 3 & 3 \\
\hline ICP.w.Ni & $6.94 E+01$ & 194 & 33 & 11 & 5 \\
\hline ICP.w.P & $6.61 E+03$ & 49 & 10 & 5 & 3 \\
\hline IC.w.CI & $7.33 E+02$ & 5 & 3 & 3 & 2 \\
\hline IC.w.NO2 & $4: 08 E+04$ & 6 & 3 & 3 & 2 \\
\hline IC.w.NO3 & $4.03 E+0.4$ & 13 & 5 & 3 & 3 \\
\hline IC.w.PO4 & $2.05 E+04$ & 49 & 10 & 5 & 3 \\
\hline IC.w.SO4 & $7.70 E+03$ & 16 & 5 & 3 & 3 \\
\hline FREE.CN & $8.80 E+02$ & 70 & 14 & 6 & 4 \\
\hline TOTAL.CN & $8.46 E+03$ & 138 & 25 & 8 & 4 \\
\hline $\mathbf{U}$ & $1.57 E+01$ & 176 & 31 & 10 & 5 \\
\hline TA & $3.41 \mathrm{E}-01$ & 717 & 117 & 31 & 10 \\
\hline Sr-90 & $7.66 \mathrm{E}+02$ & 175 & 31 & 10 & 5 \\
\hline
\end{tabular}


WHC-SD-HM-TI-674, Rev. 0

Table A-2. Predicted Number of Core Samples Required for a Specified Half-Width of a 95\% Confidence Interval in the Mean for C-109. (sheet 2 of 2)

\begin{tabular}{|l||c|c|c|c|c|}
\hline & Mosn & \multicolumn{4}{|c|}{ Half-Width of Confidence Intorval as \% of Moan } \\
\hline \hline Analyte & $\mu \mathrm{g} / \mathrm{g}$ or $\mu \mathrm{Cl} / \mathrm{g}$ & $10 \%$ & $25 \%$ & $50 \%$ & $100 \%$ \\
\hline \hline Pu-239/240 & $3.41 \mathrm{E}-01$ & 717 & 117 & 31 & 10 \\
\hline W.Cs-137 & $7.95 \mathrm{E}+\infty$ & 35 & 8 & 4 & 3 \\
\hline f.Cs-137 & $8.20 \mathrm{E}+02$ & 36 & 8 & 4 & 3 \\
\hline
\end{tabular}


Figure A-3. C-110, Number of Cores Needed to Achieve Desired Accuracy.

10 PERCENT OF THE MEAN

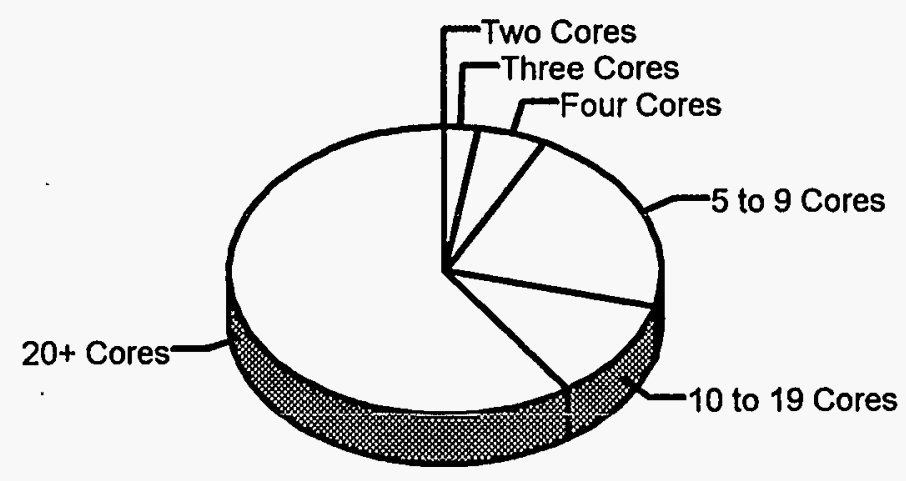

เ
25 PERCENT OF THE MEAN

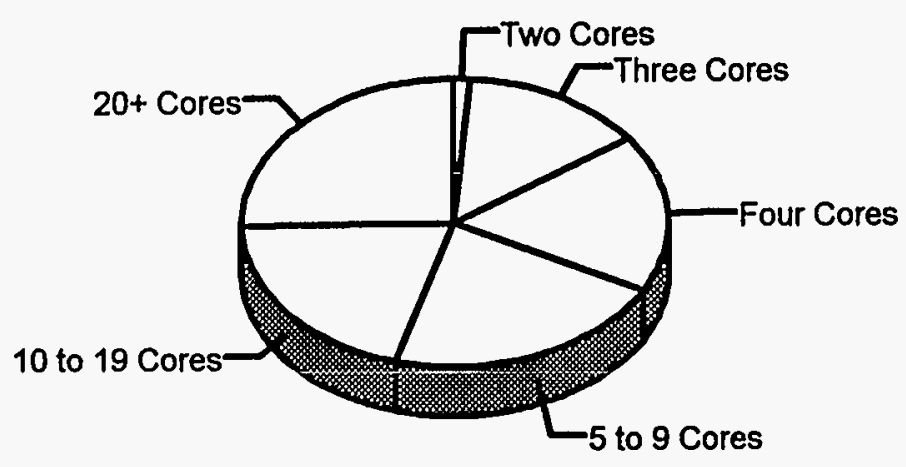

100 PERCENT OF THE MEAN

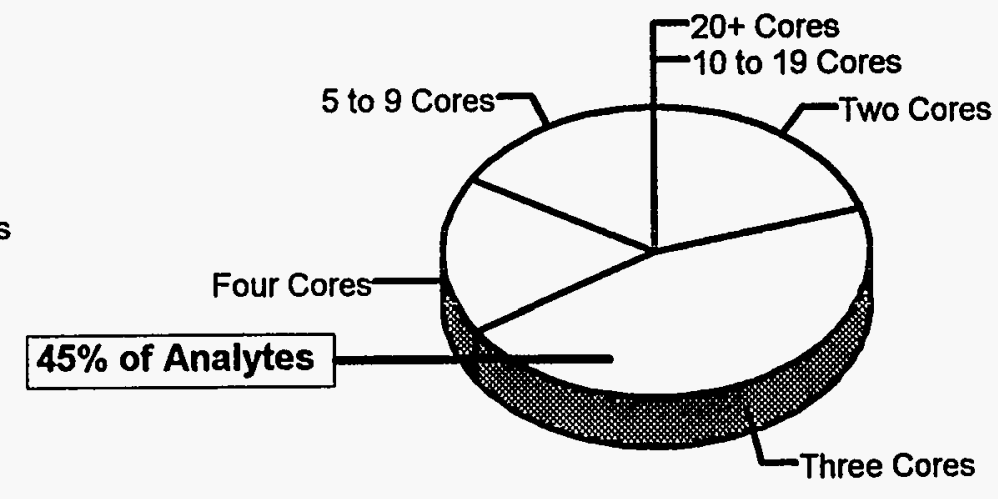

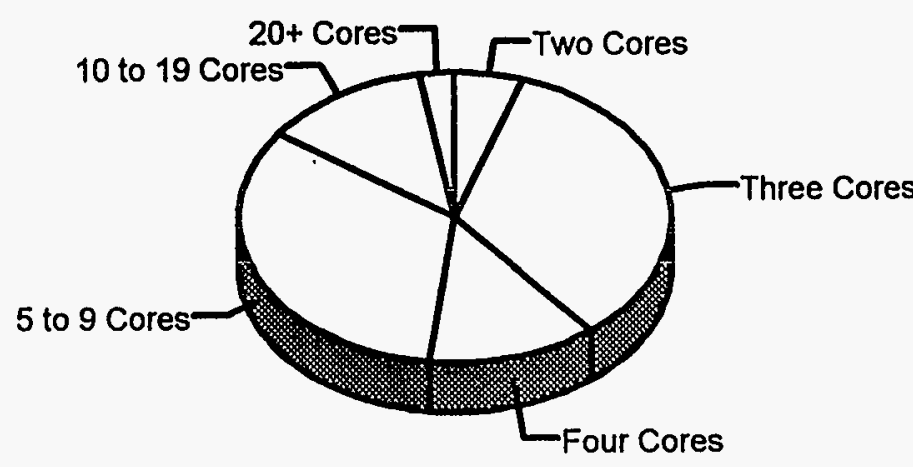


Table A-3. . Predicted Number of Core Samples Required for a Specified Half-Width of a 95\% Confidence Interval in the Mean for C-110. (sheet 1 of 3 )

\begin{tabular}{|c|c|c|c|c|c|}
\hline \multirow[b]{2}{*}{ Analyto } & \multirow{2}{*}{$\frac{\text { Moan }}{\mu g / 0 \text { or } \mu \mathrm{Ci} / \mathrm{g}}$} & \multicolumn{4}{|c|}{ Half-Width of Confidence Interval as $\%$ of Mean } \\
\hline & & $10 \%$ & $25 \%$ & $50 \%$ & $100 \%$ \\
\hline ICP.a.AI & $1.45 E+04$ & 4 & 3 & 2 & 2 \\
\hline ICP.a.B & 2.12E+01 & 14 & 5 & 3 & 3 \\
\hline ICP.a.Ba & $7.68 E+00$ & 23 & 6 & 4 & 3 \\
\hline ICP.A.Bi & $1.68 E+04$ & 8 & 4 & 3 & 3 \\
\hline ICP.a.Ca & $3.81 E+02$ & 229 & 39 & 12 & 5 \\
\hline ICP.a.Co & $2.10 E+02$ & 8 & 4 & 3 & 2 \\
\hline ICP.a.Cr & $4.70 E+02$ & 5 & 3 & 3 & 2 \\
\hline ICP.a.Cu & $3.00 E+01$ & 63 & 13 & 5 & 3 \\
\hline ICP.a.Fe & $1.10 E+04$ & 9 & 4 & 3 & 3 \\
\hline ICP.a.K & $5.57 E+02$ & 6 & 3 & 3 & 2 \\
\hline ICP.a.Mg & $1.49 E+02$ & 24 & 6 & 4 & 3 \\
\hline ICP.a.Mn & $3.58 E+01$ & 15 & 5 & 3 & 3 \\
\hline ICP.a.Na & $7.70 E+0.4^{\circ}$ & 9 & 4 & 3 & 3 \\
\hline ICP.a.Ni & $2.39 E+01$ & 40 & 9 & 4 & 3 \\
\hline ICP.a.P & $1.85 E+04$ & 11 & 4 & 3 & 3 \\
\hline ICP.a.Pb & $2.32 \mathrm{E}+\mathrm{O} 2$ & 208 & 36 & 11 & 5 \\
\hline ICP.a.S & $4.08 E+03$ & 11 & 4 & 3 & 3 \\
\hline ICP.a.Se & $7.00 E+01$ & 286 & 48 & 14 & 6 \\
\hline ICP.a.Si & $7.26 E+02$ & 77 & 15 & 6 & 4 \\
\hline ICP.A.Sr & $1.28 E+02$ & 35 & 8 & 4 & 3 \\
\hline ICP.a.TI & $5.09 E+\infty 0$ & 8 & 4 & 3 & 2 \\
\hline ICP.a.V & $6.17 E+\infty 0$ & 51 & 11 & 5 & 3 \\
\hline ICP.a.Zn & $1.39 E+02$ & 103 & 19 & 7 & 4 \\
\hline ICP.a.Zr & $4.16 E+01$ & 47 & 10 & 5 & 3 \\
\hline ICP.f.AI & $1.43 E+04$ & 3 & 3 & 2 & 2 \\
\hline ICP.f.Bi & $1.37 E+04$ & 5 & 3 & 3 & 2 \\
\hline ICP.A.Ca & $1.15 E+03$ & 128 & 23 & 8 & 4 \\
\hline ICP.t.Cr & $4.64 E+02$ & 5 & 3 & 3 & 2 \\
\hline ICP.t.Cu & $9.89 E+01$ & 187 & 32 & 10 & 5 \\
\hline ICP.f.Fe & $1.07 E+04$ & 8 & 4 & 3 & 3 \\
\hline ICP.f.Mg & $1.53 E+02$ & 8 & 4 & 3 & 3 \\
\hline ICP.f.Mn & $5.63 E+01$ & 17 & 5 & 3 & 3 \\
\hline
\end{tabular}


Table A-3. Predicted Number of Core Samples Required for a Specified Half-Width of a 95\% Confidence Interval in the Mean for C-110. (sheet 2 of 3 )

\begin{tabular}{|c|c|c|c|c|c|}
\hline \multirow[b]{2}{*}{ Analyte } & \multirow{2}{*}{ Mean } & \multicolumn{4}{|c|}{ Half-Width of Confidence Interval as \% of Mean } \\
\hline & & $10 \%$ & $25 \%$ & $50 \%$ & $100 \%$ \\
\hline ICP.f.Na & $8.26 E+04$ & 4 & 3 & 3 & 2 \\
\hline ICP.f.Ni & $7.42 E+03$ & 81 & 17 & 7 & 4 \\
\hline ICP.f.P & $2.03 E+04$ & 6 & 3 & 3 & 2 \\
\hline ICP.t.Po & $2.58 E+02$ & 160 & 28 & 9 & 5 \\
\hline ICP.f.S & $3.96 E+03$ & 16 & 5 & 3 & 3 \\
\hline ICP.t.Si & $7.16 E+03$ & 7 & 4 & 3 & 2 \\
\hline ICP.t.Sr & $1.31 E+02$ & 37 & 9 & 4 & 3 \\
\hline ICP.t.Zn & $2.24 E+02$ & 19 & 6 & 4 & 3 \\
\hline ICP.f.Zr & $1.72 E+02$ & 12 & 4 & 3 & 3 \\
\hline ICP.w.Al & $1.15 E+03$ & 137 & 24 & 8 & 4 \\
\hline ICP.w.B & $2.50 E+01$ & 14 & 5 & 3 & 3 \\
\hline ICP.w.Bi & $6.83 E+01$ & 27 & 7 & 4 & 3 \\
\hline ICP.w.Ca & $1.54 E+02$ & 154 & 27 & 9 & 4 \\
\hline ICP.w.Cr & $2.06 E+02$ & 58 & 12 & 5 & 3 \\
\hline ICP.w.Cu & $2.11 E+\infty$ & 514 & 85 & 23 & 8 \\
\hline ICP.w.Fo & $5.84 E+02$ & 400 & 66 & 19 & 7 \\
\hline ICP.w.K & $4.11 E+02$ & 42 & 9 & 5 & 3 \\
\hline ICP.w.Mg & $1.65 E+01$ & 147 & 26 & 9 & 4 \\
\hline ICP.w.Mn & $1.99 E+\infty 0$ & 368 & 61 & 18 & 7 \\
\hline ICP.w.No & $6.63 E+0.4$ & 8 & 4 & 3 & 3 \\
\hline ICP.w.P & $7.66 \mathrm{E}+03$ & 136 & 24 & 8 & 4 \\
\hline ICP.w.S & $3.65 E+03$ & 51 & 11 & 5 & 3 \\
\hline ICP.w.Se & $4.92 E+01$ & 116 & 21 & 8 & 4 \\
\hline ICP.w.Si & $2.36 E+02$ & 101 & 19 & 7 & 4 \\
\hline ICP.w.Sr & $5.25 E+\infty$ & 404 & 67 & 19 & 7 \\
\hline ICP.w.Zn & $1.13 E+01$ & 210 & 36 & 11 & 5 \\
\hline ICP.w.Zr & $1.18 E+01$ & 346 & 58 & 17 & 6 \\
\hline IC.w.Cl & $1.06 E+03$ & 72 & 14 & 6 & 4 \\
\hline IC.w.F & $7.63 E+03$ & 22 & 6 & 4 & 3 \\
\hline IC.w.NO2 & $6.89 E+03$ & 228 & 39 & 12 & 5 \\
\hline IC.W.NO3 & $1.10 E+05$ & 8 & 4 & 3 & 3 \\
\hline
\end{tabular}


Table A-3. Predicted Number of Core Samples Required for a Specified Half-Width of a $95 \%$ Confidence Interval in the Mean for C-110. (sheet 3 of 3 )

\begin{tabular}{|c|c|c|c|c|c|}
\hline & Mean & \multicolumn{4}{|c|}{ Half-Width of Confidence Interval as \% of Mean } \\
\hline Ansilyte & $\mu \mathrm{g} / \mathrm{g}$ or $\mu \mathrm{Ci} / \mathrm{g}$ & $10 \%$ & $25 \%$ & $50 \%$ & $100 \%$ \\
\hline IC.w.PO4 & $2.81 E+0.4$ & 77 & 15 & 6 & 4 \\
\hline IC.w.SO4 & $1.48 E+04$ & 49 & 10 & 5 & 3 \\
\hline Spec.w.NO2 & $9.29 E+03$ & 91 & 17 & 7 & 4 \\
\hline Fluor.U & $1.48 E+03$ & 42 & 9 & 5 & 3 \\
\hline TA & $1.25 E-01$ & 7 & 4 & 3 & 2 \\
\hline TB & $4.24 E+01$ & 5 & 3 & 3 & 2 \\
\hline GEA.C8-137 & $1.95 E+01$ & 22 & 6 & 4 & 3 \\
\hline Pu239/40 & 8.02E-02 & 45 & 10 & 5 & 3 \\
\hline GEA.Tc-99 & 3.27E-02 & 51 & 11 & 5 & 3 \\
\hline GEA.Sr-90 & $4.92 E+\infty 0$ & 57 & 12 & 5 & 3 \\
\hline GEA.H-3 & $1.18 E-03$ & 36 & 8 & 4 & 3 \\
\hline GEA.C-14 & 4.59E-04 & 108 & 20 & 7 & 4 \\
\hline GEA.Se-79 & $1.98 \mathrm{E}-03$ & 566 & 93 & 25 & 9 \\
\hline Dir.TGA & $5.75 E+01$ & 4 & 3 & 3 & 2 \\
\hline Dir. \%water & $5.98 E+01$ & 4 & 3 & 2 & 2 \\
\hline pH & $1.10 E+01$ & 3 & 2 & 2 & 2 \\
\hline
\end{tabular}




\section{Figure A-4. C-112, Number of Cores}

Needed to Achieve Desired Accuracy.

10 PERCENT OF THE MEAN

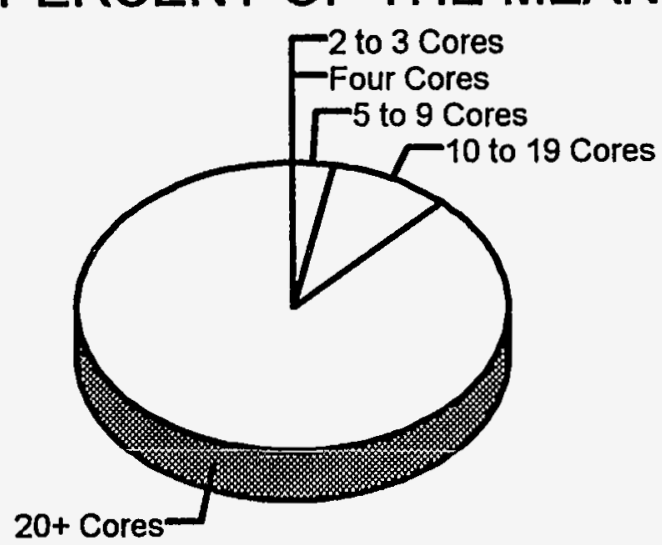

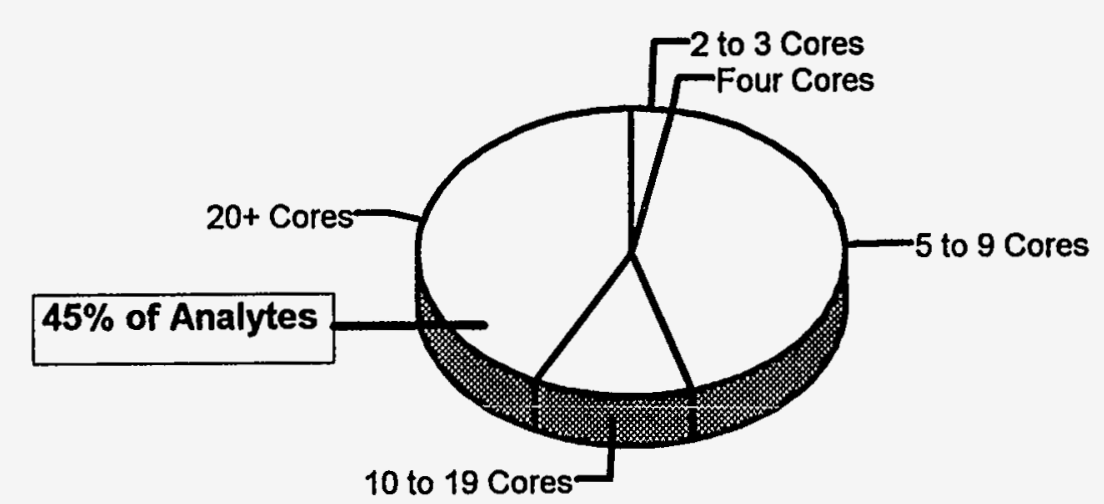

100 PERCENT OF THE MEAN

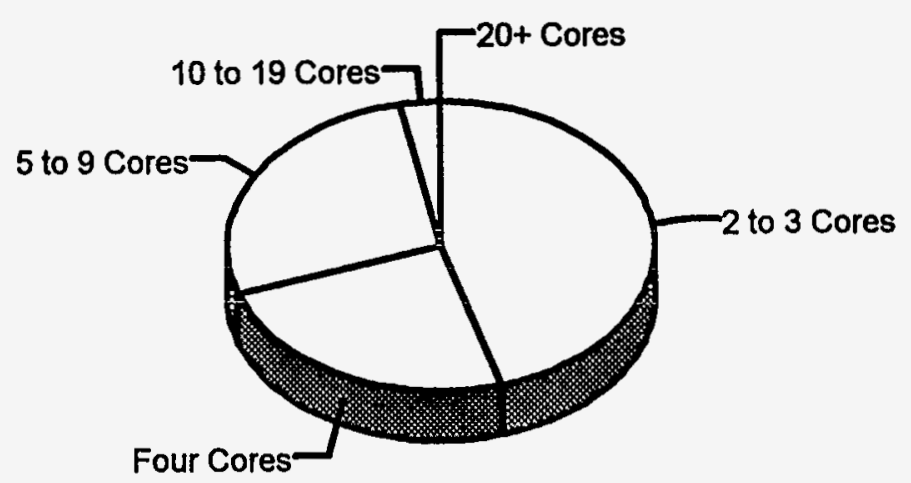
25 PERCENT OF THE MEAN

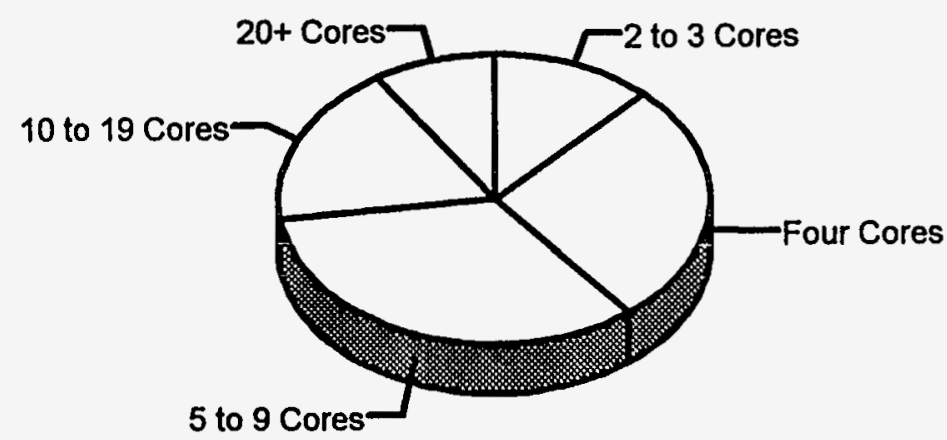

50 PERCENT OF THE MEAN

5 to 9 Cores 
WHC-SD-WM-TI-674, Rev. 0

Table A-4. Predicted Number of Core Samples Required for a Specified Half-Width of a 95\% Confidence Interval in the Mean for C-112. (sheet 1 of 2)

\begin{tabular}{|c|c|c|c|c|c|}
\hline & Mean & \multicolumn{4}{|c|}{ Half-Width of Confidence Interval as $\%$ of Mean } \\
\hline Analyte & $\mu \mathrm{g} / \mathrm{a}$ or $\mu \mathrm{Ci} / \mathrm{a}$ & $10 \%$ & $25 \%$ & $50 \%$ & $100 \%$ \\
\hline ICP.A.AI & $2.45 E+04$ & 248 & 42 & 13 & 5 \\
\hline ICP.a.Ca & 1.67E + 04 & 38 & 8 & 4 & 3 \\
\hline ICP.a.Fo & 2.19E +04 & 14 & 5 & 3 & 3 \\
\hline ICP.a.Na & $8.96 E+04$ & 16 & 5 & 3 & 3 \\
\hline ICP.a.Ni & $1.31 E+04$ & 39 & $9^{\circ}$ & 4 & 3 \\
\hline ICP.a.P & $2.28 E+04$ & 37 & 9 & 4 & 3 \\
\hline ICP.a.Pb & $2.55 E+03$ & 138 & 25 & 8 & 4 \\
\hline ICP.a.U & $5.84 E+04$ & 185 & 32 & 10 & 5 \\
\hline ICP.f.AI & $2.65 E+0.4$ & 259 & 44 & 13 & 6 \\
\hline ICP.t.Ca & $2.00 E+04$ & 42 & 9 & 5 & 3 \\
\hline ICP.f.Fe & $2.79 E+04$ & 14 & 5 & 3 & 3 \\
\hline ICP.t.Na & $1.04 E+05$ & 22 & 6 & 4 & 3 \\
\hline ICP.f.P & $2.80 E+04$ & 42 & 9 & 5 & 3 \\
\hline ICP.f.PB & $2.94 E+03$ & 183 & 32 & 10 & 5 \\
\hline ICP.f.U & B.07E+04 & 108 & 20 & 7 & 4 \\
\hline ICP.w.AI & $5.21 E+02$ & 125 & 22 & 8 & 4 \\
\hline ICP.w.Ca & $3.38 E+02$ & 66 & 13 & 6 & 4 \\
\hline ICP.w.Fe & $1.17 E+03$ & 67 & 13 & 6 & 4 \\
\hline ICP.W.Na & $8.85 E+04$ & 40 & 9 & 4 & 3 \\
\hline ICP.W.NI & $6.79 E+02$ & 75 & 14 & 6 & 4 \\
\hline ICP.w.P & $1.01 E+04$ & 156 & 27 & $9^{\circ}$ & 5 \\
\hline ICP.w.U & $2.17 E+03$ & 482 & 80 & 22 & 8 \\
\hline IC.w.Cl & $9.80 E+02$ & 29 & 7 & 4 & 3 \\
\hline IC.w.NO2 & $4.72 E+04$ & 32 & 8 & 4 & 3 \\
\hline IC.w.NO3 & $6.20 E+04$ & 37 & 8 & 4 & 3 \\
\hline IC.w.PO4 & $3.08 E+04$ & 146 & 26 & 9 & 4 \\
\hline IC.w.SO4 & $1.20 E+04$ & 36 & 8 & 4 & 3 \\
\hline Froo $\mathrm{CN}$ & $1.25 E+03$ & 85 & 16 & 6 & 4 \\
\hline $\mathbf{U}$ & $6.86 E+04$ & 240 & 41 & 12 & 5 \\
\hline Sr-90 & $2.19 E+03$ & 240 & 41 & 12 & 5 \\
\hline
\end{tabular}


WHC-SD-WM-TI-674, Rev. O

Table A-4. Predicted Number of Core Samples Required for a Specified Half-Width of a 95\% Confidence Interval in the Mean for C-112.

\begin{tabular}{|c|c|c|c|c|c|}
\hline \multirow[b]{2}{*}{ Analyte } & \multirow{2}{*}{$\frac{\text { Moan }}{\mu \mathrm{g} / \mathrm{g} \text { or } \mu \mathrm{Ci} / \mathrm{g}}$} & \multicolumn{4}{|c|}{ Half-Width of Confidence Interval as \% of Mosn } \\
\hline & & $10 \%$ & $25 \%$ & $50 \%$ & $100 \%$ \\
\hline Pu-238 & $6.45 E-02$ & 837 & 136 & 36 & 11 \\
\hline Pur-239/240 & $6.02 E-02$ & 447 & 74 & 21 & 7 \\
\hline$C_{2-1} 37$ & $7.47 E+02$ & 5 & 3 & 3 & 2 \\
\hline
\end{tabular}


Figure A-5. S-104, Number of Cores Needed to Achieve Desired Accuracy.

10 PERCENT OF THE MEAN 25 PERCENT OF THE MEAN
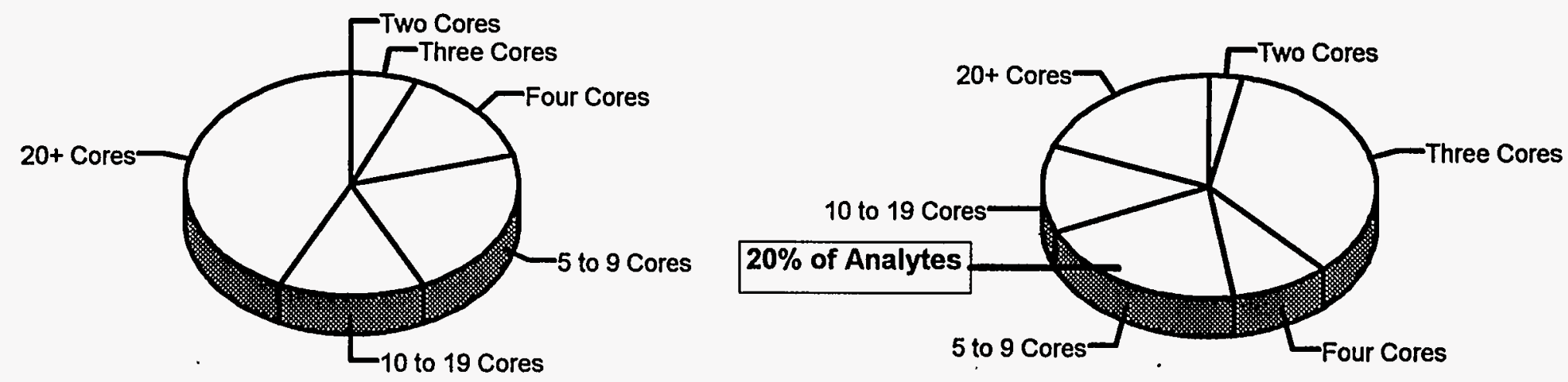

50 PERCENT OF THE MEAN

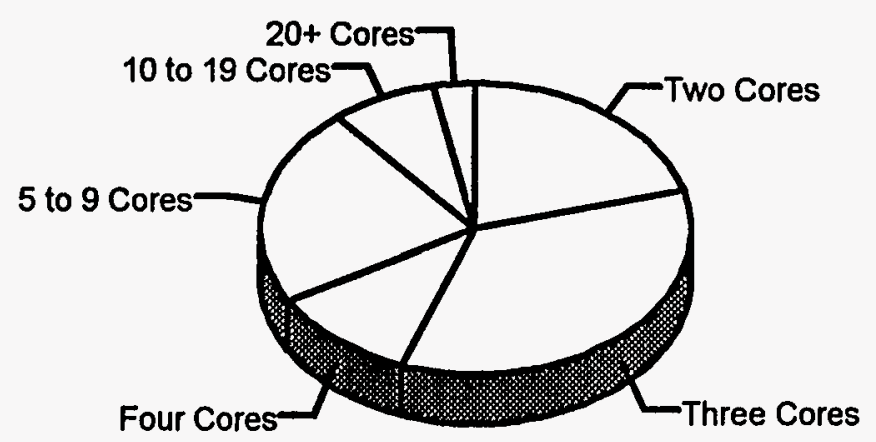

100 PERCENT OF THE MEAN

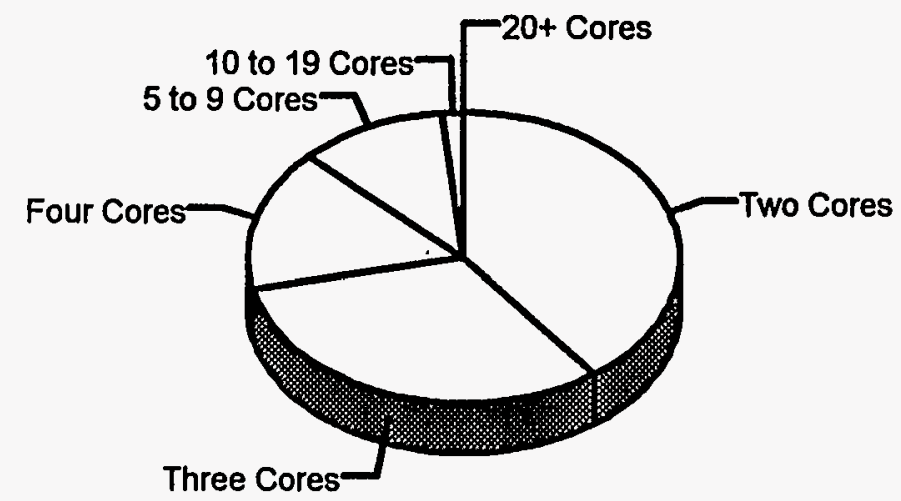


WHC-SD-WM-TI-674, Rev. 0

Table A-5. Predicted Number of Core Samples Required for a Specified Half-Width of a 95\% Confidence Interval in the Mean for S-104. (sheet 1 of 2)

\begin{tabular}{|c|c|c|c|c|c|}
\hline & Moan & \multicolumn{4}{|c|}{ Half-Width of Confidence Interval as \% of Moan } \\
\hline Analyte & $\mu \mathrm{g} / \mathrm{g}$ or $\mathrm{\mu Ci} / \mathrm{g}$ & $10 \%$ & $25 \%$ & $50 \%$ & $100 \%$ \\
\hline ICP.s.AI & $3.89 E+04$ & 41 & 8 & 5 & 3 \\
\hline ICP.a.B & $1.44 E+01$ & 71 & 14 & 6 & 4 \\
\hline ICP.a.Ba & $2.16 E+01$ & 6 & 3 & 3 & 2 \\
\hline ICP.a.Co & $2.47 \mathrm{E}+02$ & 15 & 5 & 3 & 3 \\
\hline ICP.8.Ce & $2.21 E+01$ & 8 & 4 & 3 & 2 \\
\hline ICP.a.Co & $2.52 E+\infty 0$ & 8 & 4 & 3 & 3 \\
\hline ICP.a.Cr & $2.35 E+03$ & 4 & 3 & 2 & 2 \\
\hline ICP.a.Cu & $1.94 E+01$ & 132 & 24 & 8 & 4 \\
\hline ICP.a.Fo & $7.71 E+02$ & 13 & 5 & 3 & 3 \\
\hline ICP.a.K & $3.00 E+02$ & 13 & 5 & 3 & 3 \\
\hline ICP.S.Mg & $4.28 \mathrm{E}+01$ & 20 & 6 & 4 & 3 \\
\hline ICP.a.Mn & $9.27 E+02$ & 28 & 7 & 4 & 3 \\
\hline ICP.a.Na & $1.21 E+05$ & 3 & 3 & 2 & 2 \\
\hline ICP.A.Ni & $5.60 E+01$ & 5 & 3 & 3 & 2 \\
\hline ICP.a.P & $2.12 E+01$ & 8 & 4 & 3 & 3 \\
\hline ICP.o.s & $3.94 E+02$ & 6 & 3 & 3 & 2 \\
\hline ICP.a.Si & $1.92 E+02$ & 14 & 5 & 3 & 3 \\
\hline ICP.a.Sr & $3.26 E+02$ & 5 & 3 & 3 & 2 \\
\hline ICP.a.TI & $6.35 E+\infty 0$ & 84 & 16 & 6 & 4 \\
\hline ICP.a.Zn & $2.01 E+01$ & 46 & 10 & 5 & 3 \\
\hline ICP.a.Zr & $3.36 \mathrm{E}+01$ & 4 & 3 & 2 & 2 \\
\hline$|C P . f . A|$ & $1.17 E+05$ & 3 & 2 & 2 & 2 \\
\hline ICP.f.Ba & $3.31 E+01$ & 7 & 3 & 3 & 2 \\
\hline ICP.f.Ca & $4.23 E+03$ & 739 & 121 & 32 & 10 \\
\hline ICP.f.Cr & $2.35 E+03$ & 5 & 3 & 3 & 2 \\
\hline ICP.t.Cu & $5.47 E+01$ & 26 & 7 & 4 & 3 \\
\hline ICP.f.Fe & $1.72 E+03$ & 4 & 3 & 2 & 2 \\
\hline ICP.f.Mg & $1.57 \mathrm{E}+02$ & 239 & 41 & 12 & 5 \\
\hline ICP.f.Mn & $1.15 E+03$ & 44 & 10 & 5 & 3 \\
\hline ICP.f.Na & $1.18 E+05$ & 3 & 2 & 2 & 2 \\
\hline ICP.f.Ni & $5.01 E+03$ & 11 & 4 & 3 & 3 \\
\hline IPC.f.P & $9.31 E+01$ & 11 & 4 & 3 & 3 \\
\hline
\end{tabular}


Table A-5. Predicted Number of Core Samples Required for a Specified Half-Width of a 95\% Confidence Interval in the Mean for S-104. (sheet 2 of 2 )

\begin{tabular}{|c|c|c|c|c|c|}
\hline \multirow[b]{2}{*}{ Analyto } & \multirow{2}{*}{ Mean } & \multicolumn{4}{|c|}{ Half-Width of Confidence Interval as \% of Moan } \\
\hline & & $10 \%$ & $25 \%$ & $50 \%$ & $100 \%$ \\
\hline ICP.f.S & $4.72 E+02$ & 4 & 3 & 2 & 2 \\
\hline ICP.f.Si & $1.33 E+03$ & 13 & 5 & 3 & 3 \\
\hline ICP.f.Sr & $4.24 E+02$ & 5 & 3 & 3 & 2 \\
\hline ICP.f.Zn & $2.24 E+02$ & 499 & 82 & 23 & 8 \\
\hline ICP.f.Zr & $2.12 E+01$ & 97 & 18 & 7 & 4 \\
\hline ICP.w.A| & $4.68 E+03$ & 131 & 23 & 8 & 4 \\
\hline ICP.w.B & $9.08 E+\infty$ & 26 & 7 & 4 & 3 \\
\hline ICP.w.Ca & $1.56 \mathrm{E}+02$ & 163 & 29 & 9 & 5 \\
\hline ICP.w.Cr & $1.90 \mathrm{E}+03$ & 144 & 25 & 9 & 4 \\
\hline ICP.W.K & $2.53 E+02$ & 87 & 16 & 6 & 4 \\
\hline ICP.w.Mg & $8.34 \mathrm{E}+\infty 0$ & 186 & 32 & 10 & 5 \\
\hline ICP.w.Na & $9.21 E+04$ & 103 & 19 & 7 & 4 \\
\hline ICP.w.S & $3.40 E+02$ & 148 & 26 & 9 & 4 \\
\hline ICP.w.Si & $3.98 E+01$ & 211 & 36 & 11 & 5 \\
\hline IC.w.cl & $3.20 E+03$ & 4 & 3 & 2 & 2 \\
\hline IC.w.NO2 & $2.08 E+04$ & 10 & 4 & 3 & 3 \\
\hline IC.W.NO3 & $1.91 E+05$ & 4 & 3 & 2 & 2 \\
\hline IC.w.SO4 & $2.27 E+03$ & 4 & 3 & 2 & 2 \\
\hline $\mathrm{CN}$ & $3.70 E+\infty 0$ & 7 & 3 & 3 & 2 \\
\hline Porcent.H2O & $5.16 E+01$ & 204 & 35 & 11 & 5 \\
\hline Spec.w.NO2 & $2.59 E+04$ & 5 & 3 & 3 & 2 \\
\hline TIC.W.CO3 & $4.14 E+03$ & 36 & 8 & 4 & 3 \\
\hline pH & $1.29 E+01$ & 3 & 3 & 2 & 2 \\
\hline$C-14$ & 9.01E-04 & 23 & 6 & 4 & 3 \\
\hline GEA.Cs-137 & $6.23 E+01$ & 4 & 3 & 2 & 2 \\
\hline Gross,bota & $6.41 E+02$ & 216 & 37 & 12 & 5 \\
\hline $\mathrm{H}-3$ & $3.38 E-03$ & 19 & 6 & 4 & 3 \\
\hline Pu-239/40 & 2.82E-01 & 71 & 14 & 6 & 4 \\
\hline Sr-90 & $3.10 E+02$ & 4 & 3 & 2 & 2 \\
\hline Tc-99 & $2.42 E-02$ & 6 & 3 & 3 & 2 \\
\hline u & $6.69 E+03$ & 7 & 3 & 3 & 2 \\
\hline
\end{tabular}




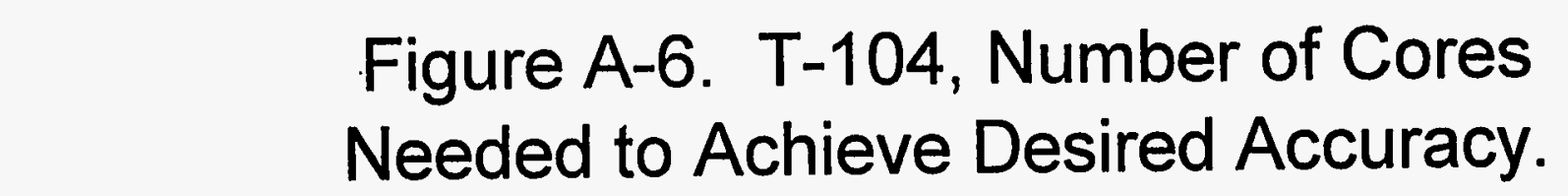

10 PERCENT OF THE MEAN

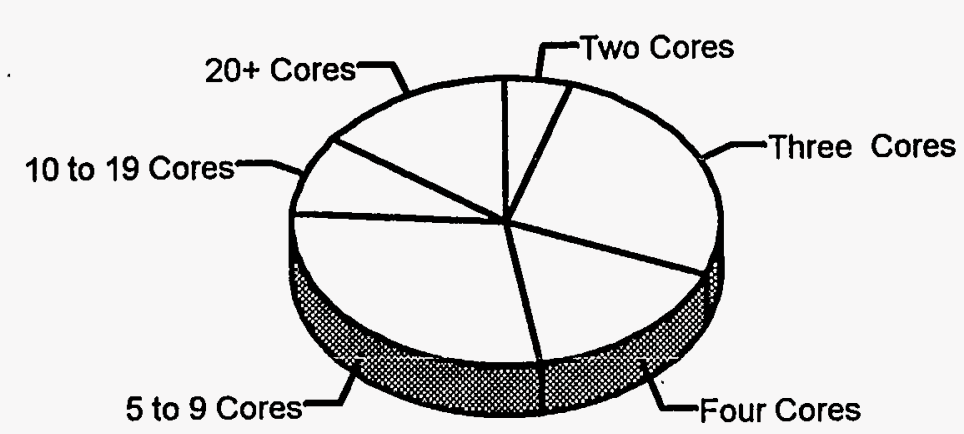

ก 25 PERCENT OF THE MEAN

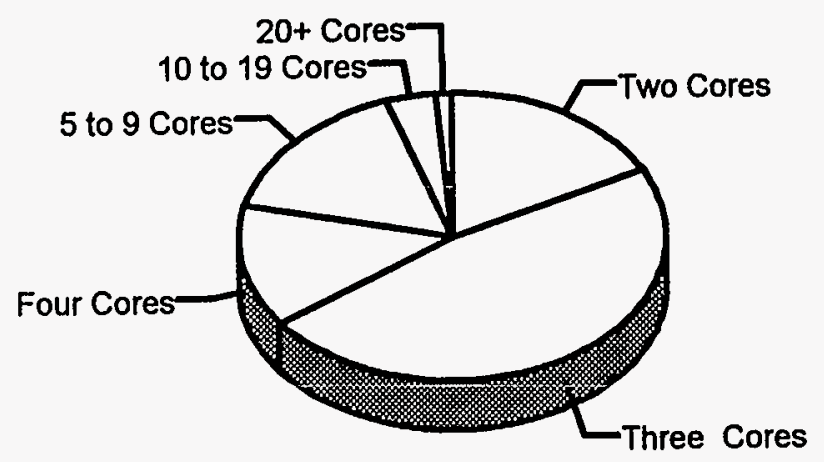

100 PERCENT OF THE MEAN

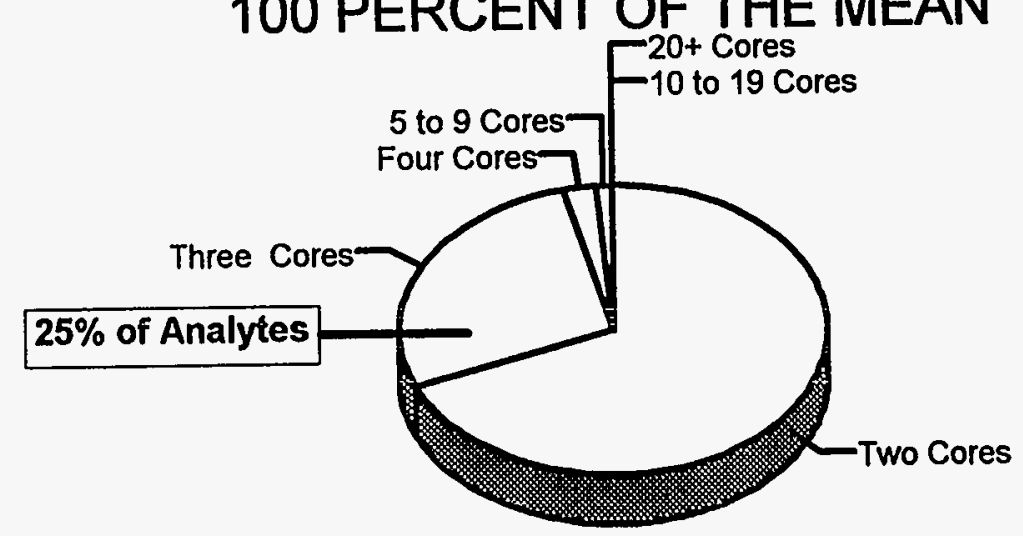

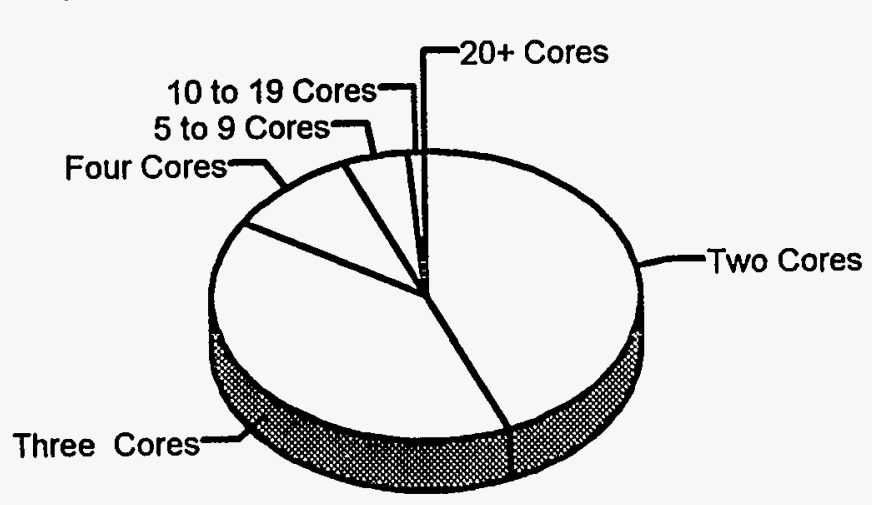


Table A-6. Predicted Number of Core Samples Required for a Specified Half-Width of a 95\% Confidence Interval in the Mean for T-104. (sheet 1 of 3 )

\begin{tabular}{|c|c|c|c|c|c|}
\hline \multirow[b]{2}{*}{ Analyte } & \multirow{2}{*}{$\frac{\text { Mean }}{\mu \alpha / 0 \text { or } \mu \mathrm{Ci} / \mathrm{g}}$} & \multicolumn{4}{|c|}{ Half-Width of Confidence Interval as \% of Mean } \\
\hline & & $10 \%$ & $25 \%$ & $50 \%$ & $100 \%$ \\
\hline ICP.a.AI & $1.62 E+04$ & 7 & 4 & 3 & 2 \\
\hline ICP.a.B & $1.56 E+01$ & 10 & 4 & 3 & 3 \\
\hline ICP.a.Ba & $7.64 E+\infty 0$ & 4 & 3 & 2 & 2 \\
\hline ICP.a.Bi & $1.89 E+04$ & 3 & 2 & 2 & 2 \\
\hline ICP.a.Ca & $2.62 E+02$ & 18 & 5 & 3 & 3 \\
\hline ICP.a.Cd & $1.69 E+00$ & 5 & 3 & 3 & 2 \\
\hline ICP.a.Ce & $1.94 E+02$ & 5 & 3 & 3 & 2 \\
\hline ICP.a.Cr & $9.01 E+02$ & 4 & 3 & 2 & 2 \\
\hline ICP.a.Cu & $1.25 E+01$ & 4 & 3 & 2 & 2 \\
\hline ICP.a.Fe & $9.02 E+03$ & 4 & 3 & 2 & 2 \\
\hline ICP.a.K & $8.90 E+01$ & 3 & 2 & 2 & 2 \\
\hline ICP.a.Mg & $1.03 E+02$ & 4 & 3 & 2 & 2 \\
\hline ICP.a.Mn & $3.06 \varepsilon+01$ & 3 & 3 & 2 & 2 \\
\hline ICP.o.Na & $6.45 E+04$ & 4 & 3 & 2 & 2 \\
\hline ICP.a.NI & $1.13 E+01$ & 26 & 7 & 4 & 3 \\
\hline ICP.a.P & $2.40 E+04$ & 3 & 3 & 2 & 2 \\
\hline ICP.a.Pb & $4.98 E+01$ & 29 & 7 & 4 & 3 \\
\hline ICP.a.s & $1.28 E+03$ & 3 & 2 & 2 & 2 \\
\hline ICP.a.Si & $1.02 E+03$ & 19 & 6 & 4 & 3 \\
\hline ICP.a.Sn & $1.16 E+01$ & 9 & 4 & 3 & 3 \\
\hline ICP.a.Sr & $9.68 E+01$ & 5 & 3 & 3 & 2 \\
\hline ICP.๑.TI & $4.56 E+\infty$ & 5 & 3 & 3 & 2 \\
\hline ICP.a.Zn & $2.35 E+01$ & 6 & 3 & 3 & 2 \\
\hline ICP.a.Zr & $6.76 \mathrm{E}+01$ & 81 & 15 & 6 & 4 \\
\hline ICP.f.AI & $1.56 \mathrm{E}+04$ & 14 & 5 & 3 & 3 \\
\hline ICP.f.Ba & $8.58 E+\infty 0$ & 3 & 3 & 2 & 2 \\
\hline ICP.f.Bi & $1.74 E+04$ & 6 & 3 & 3 & 2 \\
\hline ICP.f.Ca & $1.45 E+03$ & 219 & 37 & 12 & 6 \\
\hline ICP.f.Co & $1.60 E+02$ & 9 & 4 & 3 & 3 \\
\hline ICP.f.Cr & $8.67 E+02$ & 3 & 3 & 2 & 2 \\
\hline ICP.f.Cu & $5.10 E+01$ & 54 & 11 & 5 & 3 \\
\hline ICP.f.Fo & $8.84 E+03$ & 7 & 3 & 3 & 2 \\
\hline
\end{tabular}


WHC-SD-WM-TI-674, Rev. 0

Table A-6. Predicted Number of Core Samples Required for a Specified Half-Width of a 95\% Confidence Interval in the Mean for T-104. (sheet 2 of 3 )

\begin{tabular}{|c|c|c|c|c|c|}
\hline \multirow[b]{2}{*}{ Analyte } & \multirow{2}{*}{ Mean } & \multicolumn{4}{|c|}{ Half-Width of Confidence Interval as $\%$ of Mean } \\
\hline & & $10 \%$ & $25 \%$ & $50 \%$ & $100 \%$ \\
\hline ICP.f.Mg & $1.41 E+02$ & 20 & 6 & 4 & 3 \\
\hline ICP.f.Mn & $6.18 E+01$ & 4 & 3 & 3 & 2 \\
\hline ICP.T.Na & $6.21 E+04$ & 3 & 3 & 2 & 2 \\
\hline ICP.t.Ni & $1.05 E+04$ & 23 & 6 & 4 & 3 \\
\hline ICP.f.P & $2.47 E+04$ & 9 & 4 & 3 & 3 \\
\hline ICP.t.S & $1.27 E+03$ & 3 & 3 & 2 & 2 \\
\hline ICP.t.Si & $6.52 E+03$ & 3 & 3 & 2 & 2 \\
\hline ICP.t.Sr & $9.91 E+01$ & 4 & 3 & 2 & 2 \\
\hline ICP.f.Ti & $9.67 E+\infty$ & 20 & 6 & 4 & 3 \\
\hline ICP.f.Zn & $1.37 E+02$ & 98 & 18 & 7 & 4 \\
\hline ICP.f.Zr & $3.75 E+01$ & 7 & 4 & 3 & 2 \\
\hline ICP.W.AI & $1.58 \mathrm{E}+02$ & 8 & 4 & 3 & 3 \\
\hline ICP.W.B & $1.15 E+01$ & 5 & 3 & 3 & 2 \\
\hline ICP.w.Bi & $1.68 E+02$ & 8 & 4 & 3 & 3 \\
\hline ICP.w.Cs & $1.71 E+02$ & 7 & 3 & 3 & 2 \\
\hline ICP.w.Cr & $1.44 E+02$ & 4 & 3 & 2 & 2 \\
\hline ICP.w.Fe & $8.08 E+01$ & 7 & 4 & 3 & 2 \\
\hline ICP.w.K & $3.59 E+01$ & 4 & 3 & 2 & 2 \\
\hline ICP.w.Mg & $6.06 E+\infty 0$ & 40 & 9 & 4 & 3 \\
\hline ICP.w.Na & $4.65 E+04$ & 3 & 3 & 2 & 2 \\
\hline ICP.w.P & $6.41 E+03$ & 4 & 3 & 2 & 2 \\
\hline ICP.w.S & $1.28 E+03$ & 3 & 2 & 2 & 2 \\
\hline ICP.w.Si & $1.67 E+02$ & 3 & 3 & 2 & 2 \\
\hline ICP.w.Sr & $1.17 E+\infty$ & 18 & 5 & 3 & 3 \\
\hline ICP.w.Zr & $2.45 E+\infty$ & 6 & 3 & 3 & 2 \\
\hline IC.w.Cl & $6.70 E+02$ & 3 & 2 & 2 & 2 \\
\hline IC.w.F & 8.57E +03 & 3 & 2 & 2 & 2 \\
\hline IC.w.NO2 & $4.08 E+03$ & 2 & 2 & 2 & 2 \\
\hline IC.W.NO3 & $5.80 E+04$ & 3 & 2 & 2 & 2 \\
\hline IC.W.PO4 & $1.78 E+04$ & 5 & 3 & 3 & 2 \\
\hline IC.w.SO4 & $3.90 E+03$ & 3 & 2 & 2 & 2 \\
\hline
\end{tabular}


Table A-6. Predicted Number of Core Samples Required for a Specified Half-Width of a $95 \%$ Confidence Interval in the Mean for T-104. (sheet 3 of 3 )

\begin{tabular}{|c|c|c|c|c|c|}
\hline \multirow[b]{2}{*}{ Analyte } & \multirow{2}{*}{$\frac{\text { Mean }}{\mu \mathrm{g} / \mathrm{g} \text { or } \mu \mathrm{Ci} / \mathrm{g}}$} & \multicolumn{4}{|c|}{ Half-Width of Confidence Interval as \% of Mean } \\
\hline & & $10 \%$ & $25 \%$ & $50 \%$ & $100 \%$ \\
\hline GEA.Am-241 & $1.42 E-02$ & 6 & 3 & 3 & 2 \\
\hline GEA.Cs-137 & 1.99E-01 & 3 & 3 & 2 & 2 \\
\hline GEA.EU-155 & $3.42 E-03$ & 6 & 3 & 3 & 2 \\
\hline GEA.Grose.alphs & $1.09 E-01$ & 4 & 3 & 3 & 2 \\
\hline GEA.Gross.bota & $7.58 E+\infty 0$ & 12 & 4 & 3 & 3 \\
\hline Am-241 & $1.73 E-02$ & 5 & 3 & 3 & 2 \\
\hline Pu-239 & $9.68 E+01$ & 2 & 2 & 2 & 2 \\
\hline Pu-240 & $3.19 E+\infty 0$ & 4 & 3 & 3 & 2 \\
\hline Pu-241 & 3.99E-02 & 43 & 9 & 5 & 3 \\
\hline Spec.w.NO2 & $4.24 E+03$ & 3 & 2 & 2 & 2 \\
\hline Sr-90 & $2.63 E+\infty$ & 9 & 4 & 3 & 3 \\
\hline$u$ & $8.97 E+02$ & 3 & 3 & 2 & 2 \\
\hline U-234 & 7.25E-03 & 26 & 7 & 4 & 3 \\
\hline$U-235$ & 6.74E-01 & 3 & 2 & 2 & 2 \\
\hline U-236 & $6.75 E-03$ & 15 & 5 & 3 & 3 \\
\hline U-238 & $9.93 E+01$ & 2 & 2 & 2 & 2 \\
\hline Percent.H2O & 7.05E + 01 & 2 & 2 & 2 & 2 \\
\hline
\end{tabular}


Figure A-7. T-105, Number of Cores Needed to Achieve Desired Accuracy.

10 PERCENT OF THE MEAN

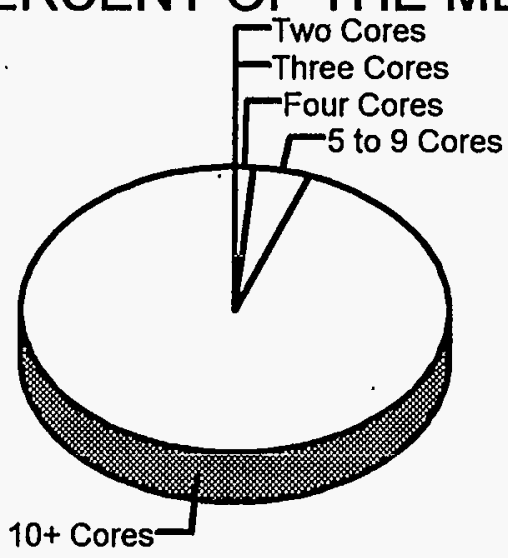

$\tilde{\Phi}$
25 PERCENT OF THE MEAN

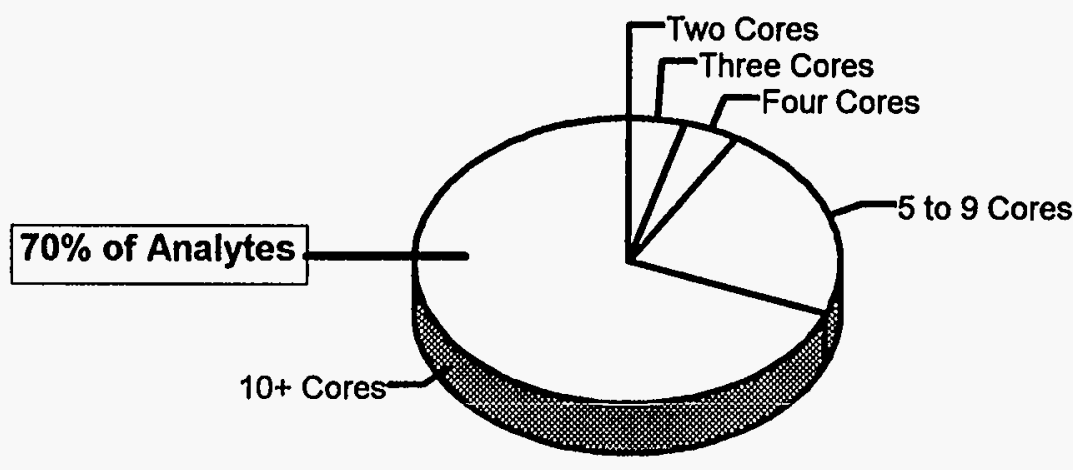

100 PERCENT OF THE MEAN

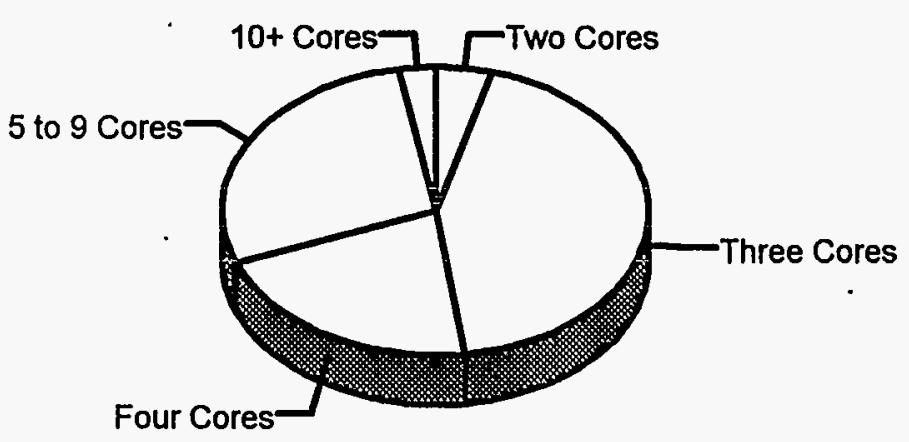

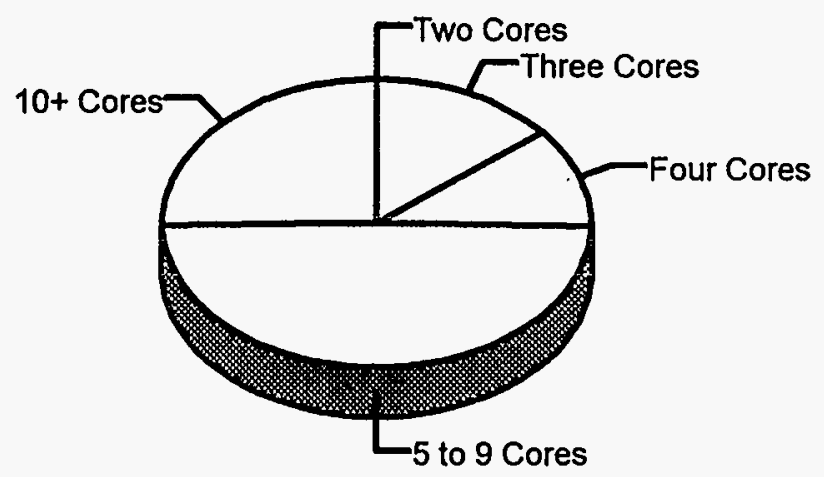


WHC-SD-WM-TI-674, Rev. 0

Table A-7. Prediçted Number of Core Samples Required for a Specified Half-Width of a 95\% Confidence Interval in the Mean for T-105. (sheet 1 of 3 )

\begin{tabular}{|c|c|c|c|c|c|}
\hline \multirow[b]{2}{*}{ Analyte } & \multirow{2}{*}{ Moon } & \multicolumn{4}{|c|}{ Half-Width of Confidence Interval } \\
\hline & & $10 \%$ & $25 \%$ & $50 \%$ & $100 \%$ \\
\hline ICP.a.Ag & $1.66 E+01$ & 31 & 8 & 4 & 3 \\
\hline |CP.o.A| & $9.24 E+04$ & 338 & 67 & 16 & 6 \\
\hline ICP.a.Bi & $1.33 E+03$ & 5 & 3 & 3 & 2 \\
\hline ICP.a.Ca & $1.42 E+03$ & 6 & 3 & 3 & 2 \\
\hline ICP.a.Cr & $5.05 E+02$ & 150 & 27 & 9 & 4 \\
\hline ICP.a.Fe & $2.73 E+0.4$ & 345 & 58 & 17 & 6 \\
\hline ICP.a.K & $3.05 E+02$ & 74 & 14 & 6 & 4 \\
\hline ICP.s. $\mathrm{Mg}$ & $1.06 E+03$ & 4 & 3 & 3 & 2 \\
\hline ICP.a.Mn & $1.16 \mathrm{E}+04$ & 394 & 65 & 19 & 7 \\
\hline ICP.a.Mo & $3.43 E+01$ & 30 & 7 & 4 & 3 \\
\hline ICP.a.Na & $5.63 E+04$ & 39 & 9 & 4 & 3 \\
\hline ICP.o.Ni & 8.13E+01 & 30 & 7 & 4 & 3 \\
\hline ICP.a.P & $1.49 E+03$ & 37 & 8 & 4 & 3 \\
\hline ICP.a.Pb & $5.34 E+02$ & 192 & 33 & 11 & 5 \\
\hline ICP.a.S & $2.61 E+03$ & 59 & 12 & 5 & 3 \\
\hline ICP.a.Si & $1.16 E+03$ & 678 & 111 & 30 & 10 \\
\hline ICP.\&.Sr & $1.48 E+02$ & 16 & 5 & 3 & 3 \\
\hline ICP.a.Ti & $5.88 E+01$ & 22 & 6 & 4 & 3 \\
\hline ICP.a.Zr & $5.08 E+01$ & 434 & 72 & 20 & 7 \\
\hline ICP.f.Ag & 4.62E+01 & 195 & 34 & 11 & 5 \\
\hline ICP.f.AI & $9.51 E+04$ & 268 & 45 & 14 & 6 \\
\hline ICP.f.BI & $1.22 E+03$ & 17 & 5 & 3 & 3 \\
\hline ICP.f.Ca & $3.67 E+03$ & 112 & 20 & 7 & 4 \\
\hline ICP.t.Cd & $1.54 E+01$ & 50 & 11 & 5 & 3 \\
\hline ICP.f.Co & $7.90 E+01$ & 137 & 24 & 8 & 4 \\
\hline ICP.f.Cr & $4.32 E+02$ & 137 & 24 & 8 & 4 \\
\hline ICP.f.Fo & $3.31 E+04$ & 43 & 9 & 5 & 3 \\
\hline ICP.f.LI & $3.59 E+\infty 0$ & 28 & 7 & 4 & 3 \\
\hline ICP.T.Mg & $1.10 E+03$ & 16 & 5 & 3 & 3 \\
\hline ICP.t.Mn & $1.04 E+04$ & 411 & 68 & 19 & 7 \\
\hline ICP.t.Mo & $3.17 \mathrm{E}+01$ & 50 & 11 & 5 & 3 \\
\hline ICP.t.Na & $4.92 E+04$ & 56 & 91 & 5 & 3 \\
\hline
\end{tabular}


Table A-7. Predicted Number of Core Samples Required for a Specified Half-Width of a 95\% Confidence Interval in the Mean for T-105. (sheet 2 of 3 )

\begin{tabular}{|c|c|c|c|c|c|}
\hline \multirow[b]{2}{*}{ Analyte } & \multirow{2}{*}{$\frac{\text { Moan }}{\mu \mathrm{g} / \mathrm{g} \text { or } \mu \mathrm{Ci} / \mathrm{g}}$} & \multicolumn{4}{|c|}{ Half-Width of Confidence Interval } \\
\hline & & $10 \%$ & $25 \%$ & $50 \%$ & $100 \%$ \\
\hline ICP.f.P & $1.53 E+03$ & 61 & 12 & 5 & 3 \\
\hline ICP.f.Pb & $4.53 E+02$ & 89 & 17 & 6 & 4 \\
\hline ICP.f.S & $2.62 E+03$ & 84 & 16 & 6 & 4 \\
\hline ICP.t.Si & $6.98 E+03$ & 13 & 5 & 3 & 3 \\
\hline ICP.f.Sr & $1.41 E+02$ & 8 & 4 & 3 & 3 \\
\hline ICP.f.TI & $2.28 E+02$ & 309 & 52 & 15 & 6 \\
\hline ICP.f.Zr & $1.19 E+02$ & 43 & 9 & 5 & 3 \\
\hline ICP.w.Al & $2.83 E+02$ & 164 & 29 & 9 & 5 \\
\hline ICP.w.B & $3.35 E+02$ & 10 & 4 & 3 & 3 \\
\hline ICP.w.Ca & $2.87 E+02$ & 272 & 46 & 14 & 6 \\
\hline ICP.w.Cr & $1.48 E+02$ & 100 & 19 & 7 & 4 \\
\hline ICP.w.Fe & $1.04 E+01$ & 431 & 71 & 20 & 7 \\
\hline ICP.w.K & $2.76 E+02$ & 98 & 18 & 7 & 4 \\
\hline ICP.w.Mg & $1.44 \mathrm{E}+01$ & 240 & 41 & 12 & 5 \\
\hline ICP.w.Mo & $3.47 E+01$ & 111 & 20 & 7 & 4 \\
\hline ICP.w.Na & $4.95 E+04$ & 42 & 9 & 5 & 3 \\
\hline ICP.w.P & $6.55 \mathrm{E}+\mathrm{O} 2$ & 103 & 19 & 7 & 4 \\
\hline ICP.w.S & $2.76 \mathrm{E}+03$ & 53 & 11 & 5 & 3 \\
\hline ICP.w.Si & $7.47 \mathrm{E}+02$ & 94 & 17 & 7 & 4 \\
\hline IC.w.Cl & $4.02 E+02$ & 59 & 12 & 5 & 3 \\
\hline IC.w.NO2 & $2.98 E+04$ & 59 & 12 & 5 & 3 \\
\hline IC.w.NO3 & $2.12 E+04$ & 58 & 12 & 5 & 3 \\
\hline IC.w.PO4 & $2.19 E+03$ & 32 & 8 & 4 & 3 \\
\hline IC.w.SO4 & $8.55 E+03$ & 59 & 12 & 5 & 3 \\
\hline GEA.w.Am-241.RS & 8.57E-01 & 395 & 66 & 19 & 7 \\
\hline GEA.w.Co-60.RS & $3.83 E-02$ & 120 & 22 & 8 & 4 \\
\hline GEA.w.Cs-137 & $3.23 E+01$ & 56 & 11 & 5 & 3 \\
\hline GEA.w.Eu-154.RS & $1.79 E+\infty$ & 357 & 60 & 17 & 7 \\
\hline GEA.w.Eu-155.RS & $2.11 E+\infty$ & 385 & 64 & 18 & 7 \\
\hline f.Gross.alpha & $6.47 E-01$ & 57 & 12 & 5 & 3 \\
\hline f.Gross.beta & $8.63 E+02$ & 161 & 28 & 9 & 5 \\
\hline
\end{tabular}


Table A-7. Predicted Number of Core Samples Required for a Specified Half-Width of a 95\% Confidence Interval in the Mean for T-105. (sheet 3 of 3 )

\begin{tabular}{|c|c|c|c|c|c|}
\hline \multirow[b]{2}{*}{ Analyte } & \multirow{2}{*}{ Mean } & \multicolumn{4}{|c|}{ Half-Width of Confidence Interval } \\
\hline & & $10 \%$ & $25 \%$ & $50 \%$ & $100 \%$ \\
\hline TIC & $5.67 E+03$ & 98 & 18 & 7 & 4 \\
\hline TOC & $4.59 E+03$ & 11 & 4 & 3 & 3 \\
\hline w.TDS.percent & 1.83E-01 & 162 & 28 & 9 & 5 \\
\hline $\mathrm{Hg}$ & $2.39 E+01$ & 227 & 39 & 12 & 5 \\
\hline CN & $1.14 E+01$ & 158 & 28 & 9 & 5 \\
\hline w.Grose.alpha & 4.40E-03 & 42 & 9 & 5 & 3 \\
\hline w.Gross.bota & 3.77E + 01 & 67 & 13 & 6 & 4 \\
\hline H-3.RS & $1.24 \mathrm{E}-02$ & 668 & 109 & 30 & 10 \\
\hline
\end{tabular}


Figure A-8. T-107, Number of Cores Needed to Achieve Desired Accuracy.

10 PERCENT OF THE MEAN

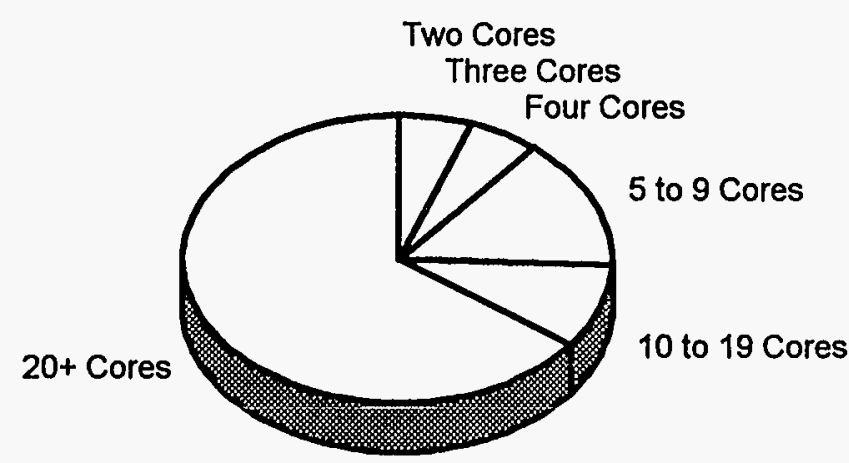

$\tilde{\infty}$
25 PERCENT OF THE MEAN

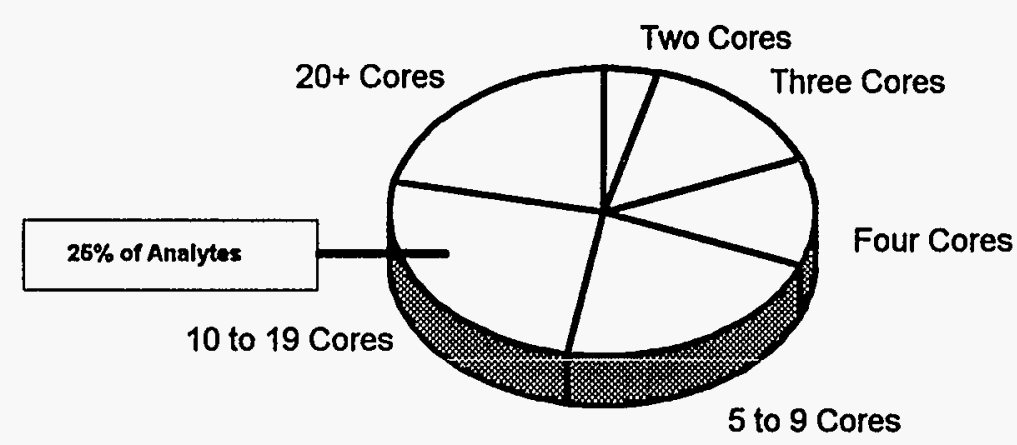

100 PERCENT OF THE MEAN

50 PERCENT OF THE MEAN
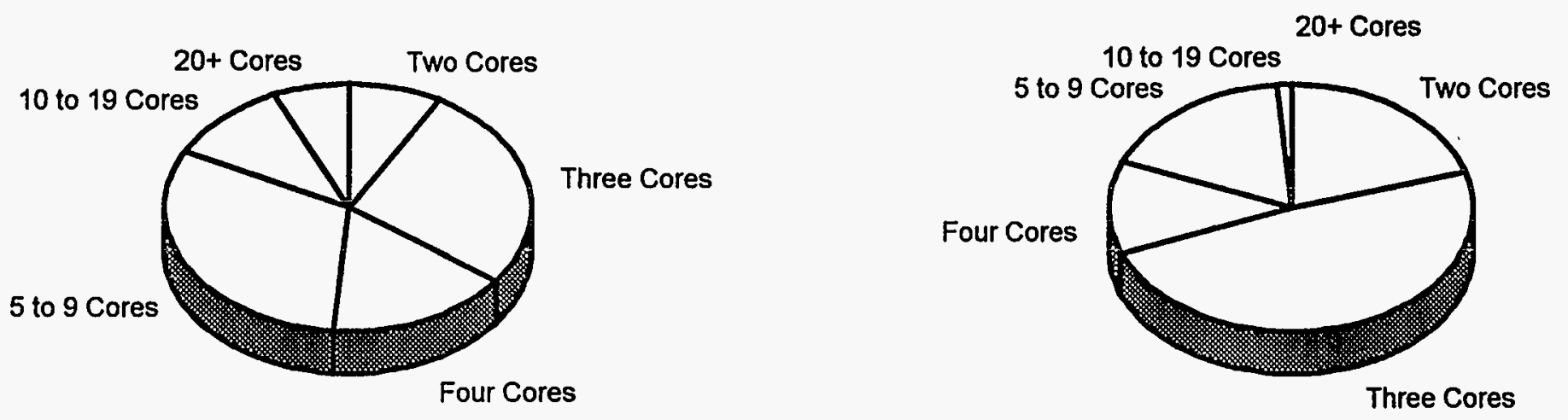
Table A-8. Predicted Number of Core Samples Required for a Specified Half-Width of a 95\% Confidence Interval in the Mean for T-107.

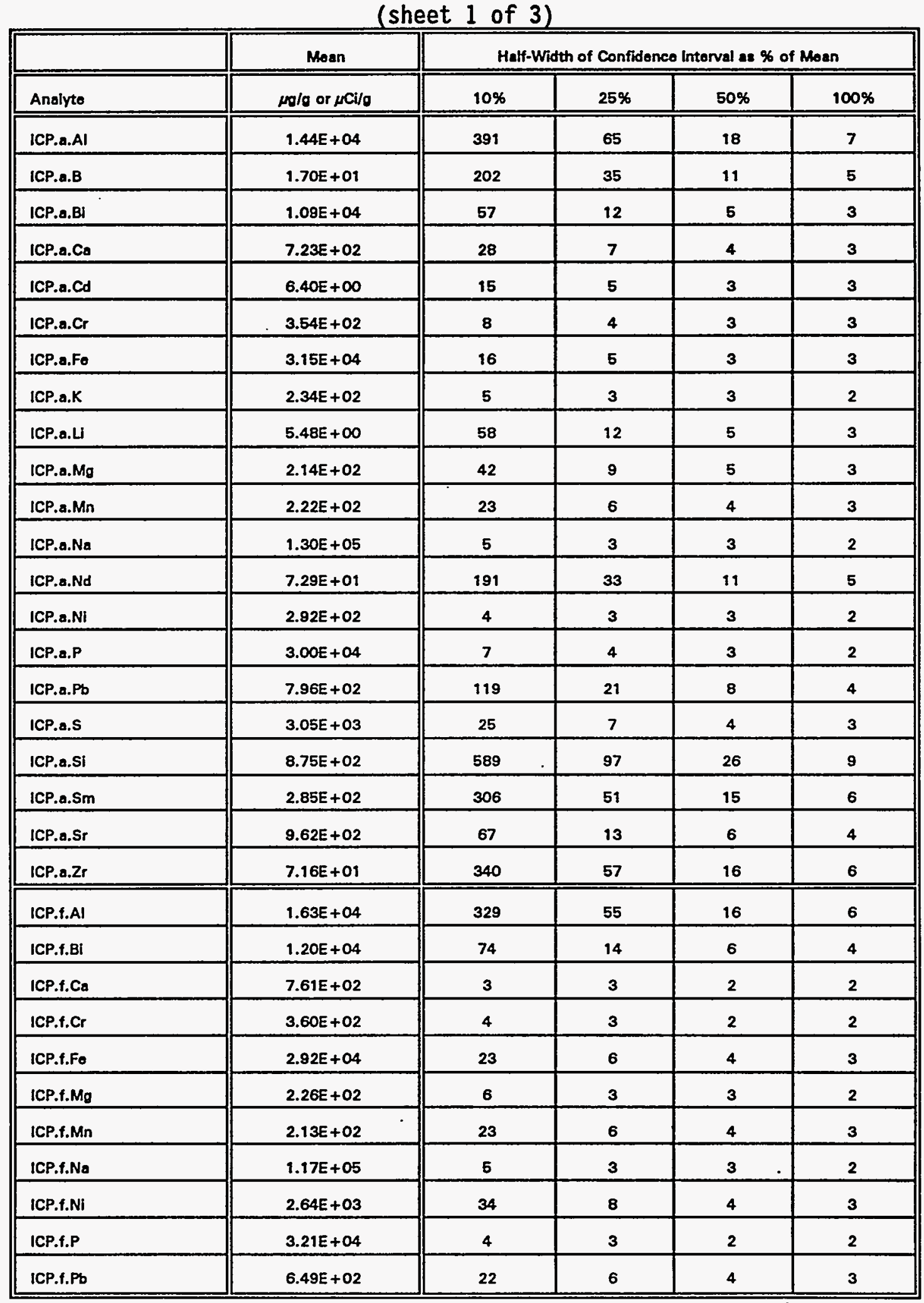


Table A-8. Predicted Number of Core Samples Required for a Specified Half-Width of a 95\% Confidence Interval in the Mean for T-107.

(sheet 2 of 3 )

\begin{tabular}{|c|c|c|c|c|c|}
\hline \multirow[b]{2}{*}{ Analyte } & \multirow{2}{*}{$\frac{\text { Mean }}{\mu \mathrm{g} / \mathrm{g} \text { or } \mu \mathrm{Ci} / \mathrm{g}}$} & \multicolumn{4}{|c|}{ Half-Width of Confidence Interval as \% of Mean } \\
\hline & & $10 \%$ & $25 \%$ & $50 \%$ & $100 \%$ \\
\hline ICP.f.S & $3.28 E+03$ & 9 & 4 & 3 & 3 \\
\hline ICP.f.Si & $6.06 E+03$ & 33 & 8 & 4 & 3 \\
\hline ICP.t.Sr & $8.78 E+02$ & 9 & 4 & 3 & 3 \\
\hline ICP.f.Zr & $8.32 E+01$ & 29 & 7 & 4 & 3 \\
\hline ICP.w.AI & $6.51 E+02$ & 53 & 11 & 5 & 3 \\
\hline ICP.w.B & $3.26 E+02$ & 699 & 114 & 31 & 10 \\
\hline ICP.w.Bi & $2.43 E+02$ & 290 & 49 & 14 & 6 \\
\hline ICP.w.Ca & 2.71E + 02 & 442 & 73 & 21 & 7 \\
\hline ICP.w.Cr & $2.11 E+02$ & 6 & 3 & 3 & 2 \\
\hline ICP.w.Fe & $3.56 E+02$ & 45 & 10 & 5 & 3 \\
\hline ICP.w.K & $3.16 \mathrm{E}+02$ & 143 & 25 & 9 & 4 \\
\hline ICP.w.Mg & $9.83 E+\infty 0$ & 11 & 4 & 3 & 3 \\
\hline ICP.w.Mo & $7.88 E+00$ & 11 & 4 & 3 & 3 \\
\hline ICP.w.No & $1.08 E+05$ & 48 & 10 & 5 & 3 \\
\hline ICP.w.S & $3.54 E+03$ & 14 & 5 & 3 & 3 \\
\hline ICP.w.Se & $6.67 E+01$ & 53 & 11 & 5 & 3 \\
\hline ICP.w.Sr & $5.53 E+\infty 0$ & 8 & 4 & 3 & 3 \\
\hline ICP.w.Zr & $6.07 E+\infty$ & 440 & 73 & 20 & 7 \\
\hline IC.w.F & $1.14 E+04$ & 31 & 8 & 4 & 3 \\
\hline IC.w.Cl & $5.41 E+02$ & 55 & 11 & 5 & 3 \\
\hline IC.w.NO2 & $1.17 E+04$ & 75 & 15 & 6 & 4 \\
\hline IC.w.NO3 & $7.45 E+04$ & 49 & 10 & 5 & 3 \\
\hline IC.w.PO4 & $1.14 E+05$ & 24 & 6 & 4 & 3 \\
\hline IC.w.SO4 & $9.89 E+03$ & 63 & 13 & 5 & 3 \\
\hline TDS(wt \%) & $3.95 E-01$ & 3 & 2 & 2 & 2 \\
\hline RS(wt\%) & $2.87 E+01$ & 10 & 4 & 3 & 3 \\
\hline $\mathrm{CN}$ & $6.88 \mathrm{E}+01$ & 88 & 17 & 6 & 4 \\
\hline Spec.w.NO2 & $1.11 E+04$ & 64 & 13 & 5 & 3 \\
\hline TIC & $4.23 E+03$ & 83 & 17 & 7 & 4 \\
\hline TOC & $1.70 E+03$ & 21 & 6 & 4 & 3 \\
\hline TA & 2.70E-03 & 504 & 83 & 23 & 8 \\
\hline
\end{tabular}


WHC-SD-WM-TI-674, Rev. 0

Table A-8. Predicted Number of Core Samples Required for a Specified Half-Width of a 95\% Confidence Interval in the Mean for T-107. (sheet 3 of 3 )

\begin{tabular}{|c|c|c|c|c|c|}
\hline \multirow[b]{2}{*}{ Analyte } & \multirow{2}{*}{$\frac{\text { Moan }}{\mu \mathrm{g} / \mathrm{o} \text { or } \mu \mathrm{Cl} / \mathrm{g}}$} & \multicolumn{4}{|c|}{ Haff-Width of Confidence Interval as $\%$ of Mean } \\
\hline & & $10 \%$ & $25 \%$ & $50 \%$ & $100 \%$ \\
\hline TB & $1.34 E+01$ & 44 & $10^{\circ}$ & 5 & 3 \\
\hline C-14 & $1.81 E-04$ & 70 & 14 & 6 & 4 \\
\hline $\mathrm{H}-3$ & $1.24 E-03$ & $\$ 1$ & 4 & 3 & 3 \\
\hline GEA.C\&-137 & $9.25 E+\infty 0$ & 71 & 14 & 6 & 4 \\
\hline RS.GEA.C8-137 & $1.20 E+01$ & 160 & 28 & 9 & 5 \\
\hline RS.GEA.Co-60 & $1.85 E-02$ & 251 & 43 & 13 & 5 \\
\hline RS.GEA.EU-154 & $1.33 E-01$ & 5 & 3 & 3 & 2 \\
\hline RS.GEA.K-40 & $3.76 E-02$ & 3 & 2 & 2 & 2 \\
\hline \%Solids & $5.02 E+01$ & 4 & 3 & 3 & 2 \\
\hline pH & $1.15 E+01$ & 3 & 2 & 2 & 2 \\
\hline Dir.CN & $7.61 E+01$ & 55. & 11 & 5 & 3 \\
\hline
\end{tabular}


Figure A-9. T-111, Number of Cores Needed to Achieve Desired Accuracy.

10 PERCENT OF THE MEAN

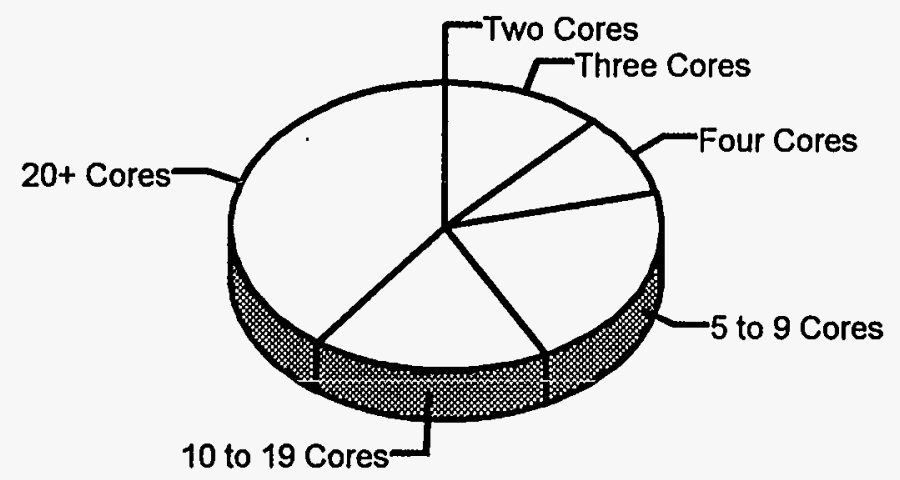

25 PERCENT OF THE MEAN

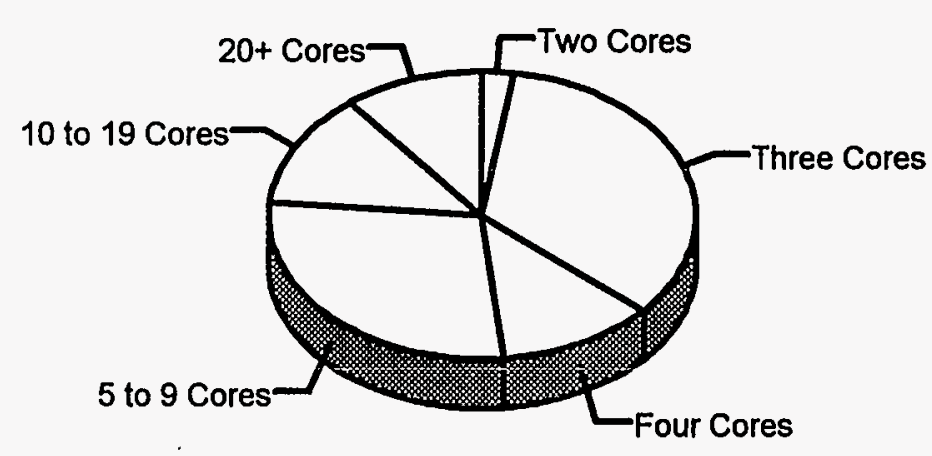

100 PERCENT OF THE MEAN

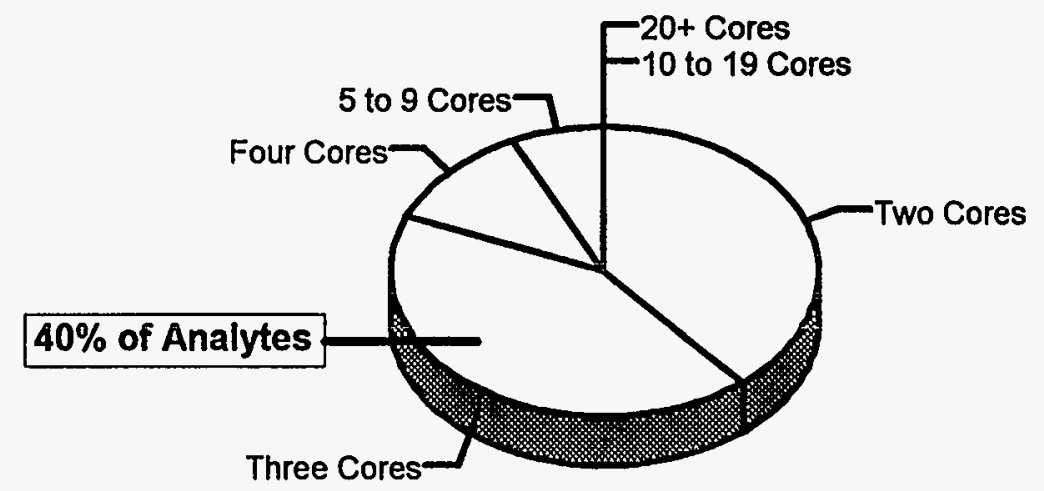

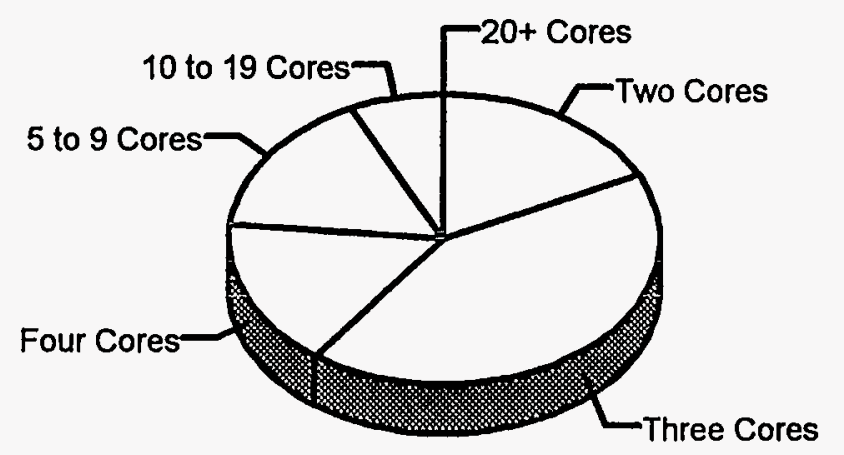


WHC-SD-WM-TI-674, Rev. 0

Table A-9. Predicted Number of Core Samples Required for a Specified Half-Width of a 95\% Confidence Interval in the Mean for T-111. (sheet 1 of 3 )

\begin{tabular}{|c|c|c|c|c|c|}
\hline \multirow[b]{2}{*}{ Analyto } & \multirow{2}{*}{ Moan } & \multicolumn{4}{|c|}{ Half-Width of Confidence Interal as $\%$ of Moan } \\
\hline & & $10 \%$ & $25 \%$ & $50 \%$ & $100 \%$ \\
\hline ICP.o.Ag & $1.26 E+02$ & 384 & 64 & 18 & 7 \\
\hline ICP.a.AI & $5.41 E+02$ & 31 & 7 & 4 & 3 \\
\hline ICP.a,B & $2.80 E+01$ & 10 & 4 & 3 & 3 \\
\hline ICP.a,Ba & $6.90 E+01$ & 13 & 5 & 3 & 3 \\
\hline ICP.a.Bi & $2.59 E+04$ & 10 & 4 & 3 & 3 \\
\hline ICP.a.Ca & $1.88 E+03$ & 49 & 10 & 5 & 3 \\
\hline ICP.a.Cd & $5.80 E+00$ & 72 & 14 & 6 & 4 \\
\hline ICP.a.Ce & 3.37E +01 & 10 & 4 & 3 & 3 \\
\hline ICP.a.Co & $4.30 E+\infty$ & 71 & 14 & 6 & 4 \\
\hline ICP.o.Cr & $1.98 E+03$ & 6 & 3 & 3 & 2 \\
\hline ICP.a.Cu & $3.35 \mathrm{E}+01$ & 245 & 42 & 13 & 5 \\
\hline ICP.e.Fo & $1.85 E+0.4$ & 6 & 3 & 3 & 2 \\
\hline ICP.a.K & $1.14 E+03$ & 4 & 3 & 3 & 2 \\
\hline ICP.a.La & $4.22 \mathrm{E}+03$ & 16 & 5 & 3 & 3 \\
\hline ICP.a.Mg & $3.77 E+02$ & 37 & 9 & 4 & 3 \\
\hline ICP.a.Mn & $6.33 E+03$ & 3 & 3 & 2 & 2 \\
\hline ICP.a.No & $3.69 E+04$ & 4 & 3 & 2 & 2 \\
\hline ICP.a.Ni & $1.32 E+02$ & 26 & 7 & 4 & 3 \\
\hline ICP.a.P & $1.03 E+04$ & 4 & 3 & 2 & 2 \\
\hline ICP.A.Pb & $3.47 E+02$ & 172 & 30 & 10 & 5 \\
\hline ICP.a.S & $1.21 E+03$ & 3 & 3 & 2 & 2 \\
\hline ICP.a.Sb & $3.14 E+01$ & 16 & 5 & 3 & 3 \\
\hline ICP.a.Si & $4.69 \mathrm{E}+02$ & 6 & 3 & 3 & 2 \\
\hline ICP.a.Sr & $3.00 E+02$ & 6 & 3 & 3 & 2 \\
\hline ICP.a.TI & $1.95 \mathrm{E}+01$ & 285 & 48 & 14 & 6 \\
\hline ICP.a.V & $1.45 \mathrm{E}+01$ & 27 & 7 & 4 & 3 \\
\hline ICP.a.Zn & $6.50 E+01$ & 121 & 22 & 8 & 4 \\
\hline ICP.A.Ag & $1.28 \mathrm{E}+02$ & 380 & 63 & 18 & 7 \\
\hline ICP.t.AI & $5.70 E+02$ & 26 & 7 & 4 & 3 \\
\hline ICP.t.Ba & $6.46 \mathrm{E}+01$ & 8 & 4 & 3 & 2 \\
\hline ICP.f.Bi & $2.36 E+04$ & 16 & 5 & 3 & 3 \\
\hline
\end{tabular}


WHC-SD-WM-TI-674, Rev. 0

Table A-9. Predicted Number of Core Samples Required for a Specified Half-Width of a 95\% Confidence Interval in the Mean for T-111. (sheet 2 of 3 )

\begin{tabular}{|c|c|c|c|c|c|}
\hline \multirow[b]{2}{*}{ Analyte } & \multirow{2}{*}{$\frac{\text { Moan }}{\mu \rho / g \text { or } \mu \mathrm{Ci} / \mathrm{g}}$} & \multicolumn{4}{|c|}{ Half-Width of Confidence Interal as $\%$ of Mean } \\
\hline & & $10 \%$ & $25 \%$ & $50 \%$ & $100 \%$ \\
\hline ICP.f.Ca & $2.42 \mathrm{E}+03$ & 14 & 5 & 3 & 3 \\
\hline ICP.f.Cd & $8.12 E+\infty$ & 23 & 6 & 4 & 3 \\
\hline ICP.f.Co & $1.15 E+01$ & 10 & 4 & 3 & 3 \\
\hline ICP.f.Cr & $1.80 E+03$ & 3 & 3 & 2 & 2 \\
\hline ICP.f.Cu & $2.93 E+01$ & 35 & 8 & 4 & 3 \\
\hline ICP.f.Fe & $1.80 E+04$ & 13 & 5 & 3 & 3 \\
\hline ICP.f.La & $4.11 E+03$ & 17 & 5 & 3 & 3 \\
\hline ICP.f.Mg & $3.55 E+02$ & 47 & 10 & 5 & 3 \\
\hline ICP.f.Mn & $6.28 E+03$ & 3 & 3 & 2 & 2 \\
\hline ICP.f.Na & $3.70 E+04$ & 6 & 3 & 3 & 2 \\
\hline ICP.f.Ni & $8.14 E+03$ & 77 & 15 & 6 & 4 \\
\hline ICP.t.P & $1.04 E+04$ & 9 & 4 & 3 & 3 \\
\hline ICP.f.Pb & $3.65 \mathrm{E}+02$ & 57 & 12 & 5 & 3 \\
\hline ICP.f.S & $1.23 E+03$ & 9 & 4 & 3 & 3 \\
\hline ICP.f.Si & $5.67 E+03$ & 4 & 3 & 3 & 2 \\
\hline ICP.f.Sr & $2.98 \mathrm{E}+02$ & 3 & 3 & 2 & 2 \\
\hline ICP.f.TI & $4.79 E+01$ & 207 & 36 & 11 & 5 \\
\hline ICP.f.V & $1.47 E+01$ & 6 & 3 & 3 & 2 \\
\hline ICP.f.Zn & $1.06 E+02$ & 3 & 3 & 2 & 2 \\
\hline ICP.w.AI & $1.09 E+01$ & 40 & 9 & 4 & 3 \\
\hline ICP.w.B & $4.07 E+00$ & 34 & 8 & 4 & 3 \\
\hline ICP.w.Bi & $2.02 E+02$ & 48 & 10 & 5 & 3 \\
\hline ICP.w.Ca & $6.16 E+01$ & 10 & 4 & 3 & 3 \\
\hline ICP.w.Cr & $2.18 E+02$ & 3 & 3 & 2 & 2 \\
\hline ICP.w.Fe & $1.28 E+02$ & 18 & 5 & 3 & 3 \\
\hline ICP.w.K & $7.19 E+02$ & 5 & 3 & 3 & 2 \\
\hline ICP.w.La & $1.10 E+01$ & 92 & 17 & 7 & 4 \\
\hline ICP.w.Mg & $3.64 E+\infty$ & 6 & 3 & 3 & 2 \\
\hline ICP.w.Mn & $2.47 E+01$ & 33 & 8 & 4 & 3 \\
\hline ICP.w.Na & $3.30 E+04$ & 5 & 3 & 3 & 2 \\
\hline ICP.w.P & $5.68 \mathrm{E}+03$ & 4 & 3 & 2 & 2 \\
\hline
\end{tabular}


Table A-9. Predicted Number of Core Samples Required for a Specified Half-Width of a 95\% Confidence Interval in the Mean for T-111. (sheet 3 of 3 )

\begin{tabular}{|c|c|c|c|c|c|}
\hline & Moan & \multicolumn{4}{|c|}{ Half-Width of Confidence Interal as \% of Mosn } \\
\hline Analyto & $\mu \mathrm{g} / \mathrm{g}$ or $\mu \mathrm{Cl} / \mathrm{g}$ & $10 \%$ & $25 \%$ & $50 \%$ & $100 \%$ \\
\hline ICP.w.S & $1.15 E+03$ & 4 & 3 & 3 & 2 \\
\hline ICP.w.si & $5.72 E+02$ & 16 & 5 & 3 & 3 \\
\hline ICP.w.Sr & $1.96 E+00$ & 20 & 6 & 4 & 3 \\
\hline IC.w.CI & $4.50 E+02$ & 7 & 4 & 3 & 2 \\
\hline IC.w.F & $2.30 E+03$ & 97 & 18 & 7 & 4 \\
\hline IC.w.NO3 & $4.12 E+04$ & 7 & 3 & 3 & 2 \\
\hline IC.w.PO4 & $1.55 E+04$ & 8 & 4 & 3 & 3 \\
\hline IC.w.SO4 & $3.54 E+03$ & 5 & 3 & 3 & 2 \\
\hline GEA.Am-241 & 4.24E-02 & 4 & 3 & 2 & 2 \\
\hline GEA.C8-137 & $1.66 E-01$ & 96 & 18 & 7 & 4 \\
\hline Gross.alpha & 3.73E-01 & 4 & 3 & 2 & 2 \\
\hline Gross.beta & $1.51 E+01$ & 120 & 22 & 8 & 4 \\
\hline TGA.Porcent.H2O & $7.65 E+01$ & 6 & 3 & 3 & 2 \\
\hline Am-241 & $4.26 E-02$ & 5 & 3 & 3 & 2 \\
\hline $\mathrm{Hg}$ & $1.43 E+\infty 0$ & 33 & 8 & 4 & 3 \\
\hline Percent.H2O & $7.60 E+01$ & 3 & 2 & 2 & 2 \\
\hline Pu-239/40 & $1.39 \mathrm{E}-01$ & 3 & 3 & 2 & 2 \\
\hline Spec.w.NO2 & $7.93 E+02$ & 14 & 5 & 3 & 3 \\
\hline Sr.90 & $5.41 E+\infty$ & 95 & 18 & 7 & 4 \\
\hline Toc & $3.12 \mathrm{E}+03$ & 33 & 8 & 4 & 3 \\
\hline Tc-99 & $7.92 \mathrm{E}-03$ & 112 & 20 & 7 & 4 \\
\hline$\underline{u}$ & $2.79 E+03$ & 23 & 6 & 4 & 3 \\
\hline pH & $9.98 E+\infty 0$ & 3 & 2 & 2 & 2 \\
\hline
\end{tabular}


WHC-SD-WM-TI-674, Rev. 0

This page intentionally left blank. 